\title{
PHOTOVOLTAICS: New Opportunities for Utilities
}

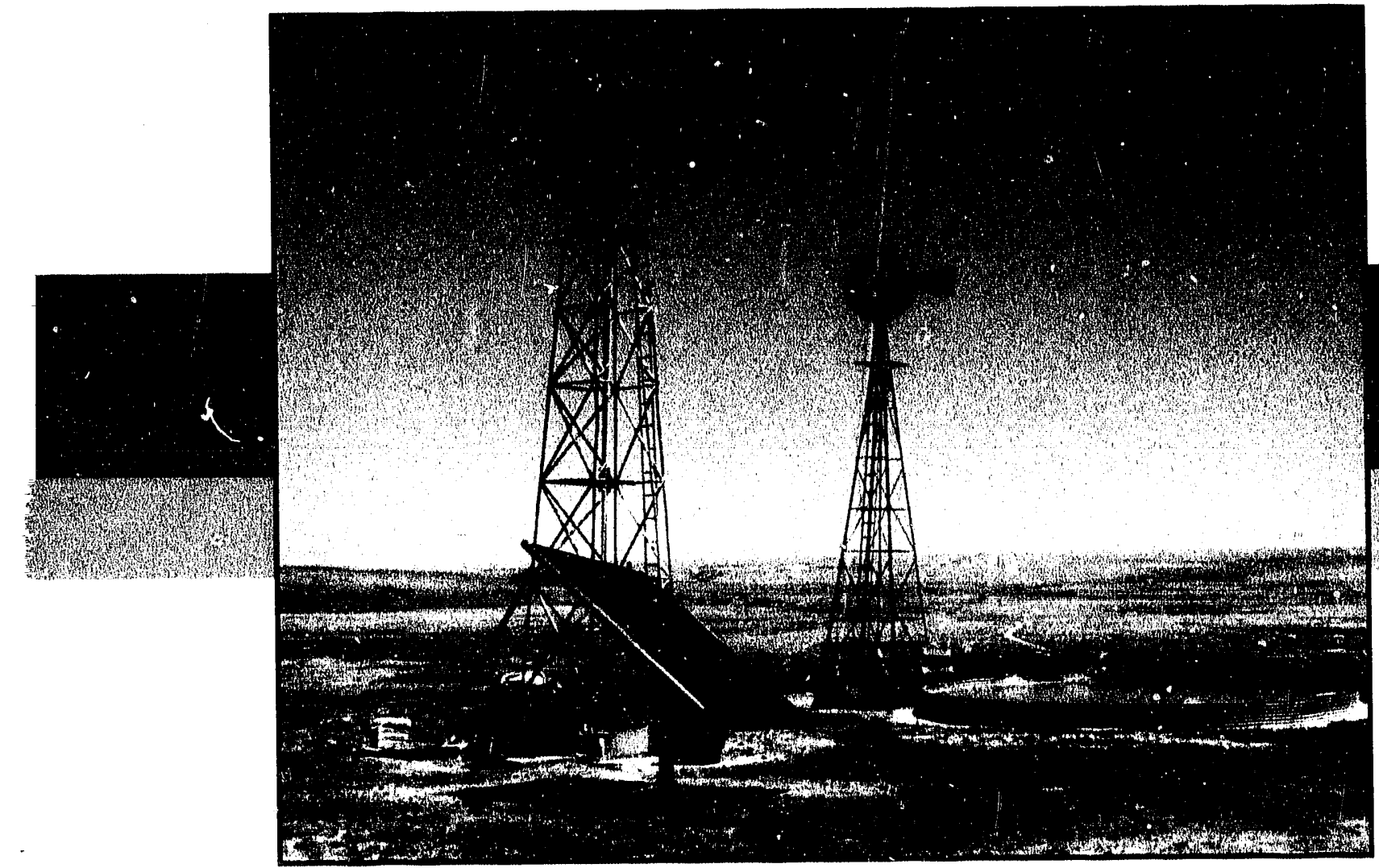

\section{Perspectives from:}

U.S. Department of Energy

New England Power Service Company

City of Austin Electric Utility Department

San Diego Gas \& Electric Company

Electric Power Research Institute

New York State Public Service Commission

Pacific Gas \& Electric Company

K.C. Electric Association

Sandia National Laboratories

Soiar Energy Research instituie 


\section{Preface}

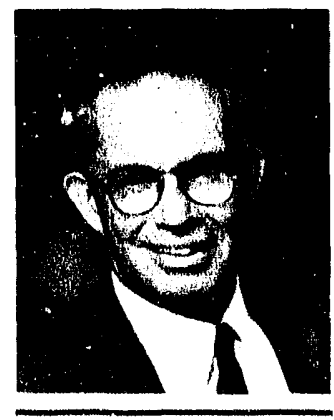

Robert H. Annan
For over a decade, the Department of Energy has supported the work of the U.S. photovoltaics industry and U.S: utilities to develop photovoltaics for utility use. Much of what we have all worked for has been realized: PV systems demonstrate the reliability and safety required for utility application; large-scale PV po'ver stations are potentially viable; costs are falling with the creation of new PV module diesigns and manufacturing processes; some line extension and remote applications are cost-effective right now.

As in all applications research, the professionals who have been working on the feasibility of photovoltaics for utility applicationis have been asking hard questions:

- How will PV modules function over timie?

- Is the PV power waveform compatible with power on the grid?

- Are there safety concerns associated with PV service?

- How well does PV's output curve in daylight hours complement typical utility demand curves?

- How can PV service be mada to work best in terms of cusiomer interface and rate structures?

The answers to these questions and many more have been encouraging. They indicate

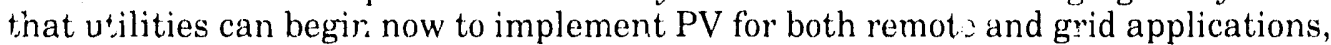
without fear that the technology will prove a dead end bocause of performance limits, waveform incompatibility, or safety concerns. In particular, the reliability and maintainability of $\mathrm{PV}$, in addition to its modularity, have been shown to be very impressive, and have become a serious economic argument in favor of the teclinology.

However, realization of PV's potential de $\mathrm{Nends}^{\prime}$ not only on basic and applied research, but on communicatir.g that demonstrated potential to the utility executive contemplat. ing future replacement and extension of generating capacity. Studies show that these executives agree with the load management and environmental objectives that PV can help them meet, but don't realize its potential fo; use in their own regions in the near future.

Bridging that gap is the mission of this compendium. 'These articles are the perspectives of professionals who have demonstrated PV's efficacy in their own situations. Regardless of your own role in providing your company's services, you'll find what these people have to say of interest. When put together with the impressive advances in cell efficiency and cost reduction emerging right now from the laboratory, their perspectives create a picture of a technology that can play a growing but cost-effective role for utiliies. It is my hope that the experiences of these executives will inspire others to consider PV in light of both its applications today and its potential for tomorrow.

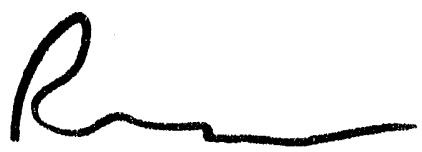

Robert H. Annan

Director, Office of Solar Energy Conversion, Conservation and Renewak.'e Energy,

U.S. Department of Energy 


\section{PHOTOVOLTAICS: New Opportunities for Utilities}

\section{Contents}

Residential Photovoltaics: The New England Experience Builds Confidence in PV . . . . . . . . . . . . . . 2 by John J. Bzura, New England Power Service Company

A hot configuration in a cold climate.

\section{Austin's 300-kW Photovoltaic Power Station:}

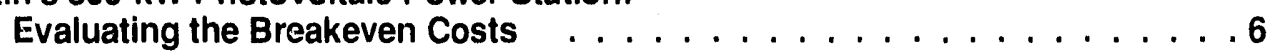

by John E. Hoffner and David C. Panico,

City of Austin Electric Utility Department

PV pioneer uses least-cost planning to weigh generating opportunities.

Residential Photovoltaics: The Lessons Learned ～. . . . . . . . . . . . . . . 9 by Skip Fralick, San Diego Gas \& Electric Company

A San Diego utility turns an enemy into an ally.

Photovoltaics for Electric Utility Use $\ldots \ldots \ldots$. . . . . . . . . . . . 11

by E.A. DeMeo, Electric Power Research Institute

Technical advances, public interest bode well for PV.

Least-Cost Planning: The Environmental Link . . . . . . . . . . . . . . . 15 by Henry G. Williams, New York State Public Service Commission

Factoring clean air into the budget.

Cover Photo:

PV proves to be more. efficient and cost-effective for some rural applications than traditional power sources. See page 20 for a discussion of K.C. Electric: Association's success with photovoltaics. (Photo courtesy of Ron White)
Photovoltaics in the Distribution System . . . . . . . . . . . . . 17 by Daniel S. Shugar, Pacific Gas \& Electric Company

PV supply can help meet the demand.

Photovoltaic Systems for the Rural Consumer . . . . . . . . . . . . . . . . 20 by J. Zabukover, K.C. Electric Association

K.C. Electric puts PV in the stock tank.

The Issues of Utility-Intertied Photovoltaics . . . . . . . . . . . . . . 23 by John Stevens, Sandia National Laboratories

The power conditioning subsystem is the key.

Photovoltaics for Large-Scale Use:

Costs Ready to Drop Again . . . . . . . . . . . . . . . . . . . . . . 27

by Ken Zweibel, Solar Energy Research Institute

Commercial progress is catching up with research.

Additional Information $\ldots \ldots \ldots \ldots \ldots$

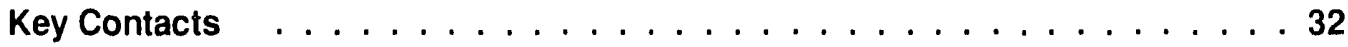




\section{Residential Photovoltaics: The New England Experience
Builds Confidence in PV}

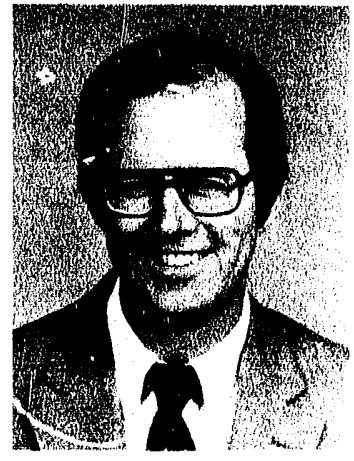

\section{A residential project in Gardner, Massachusetts demonstrates the effects of dispersed rooftop systems on a single distribution feeder. The results are impressive.}

by John J. Bzura

Principal Engineer,

New England Power Service Company

$\mathbf{T}_{1}$ he New England Electric System (NEES) is conducting a unique photovoltaic systems research and demonstration project in two of its subsidiaries: the Massachusetts Electric Company (MECo) and the Narragansett Electric Company (NECo), which is located in Rhode Island.

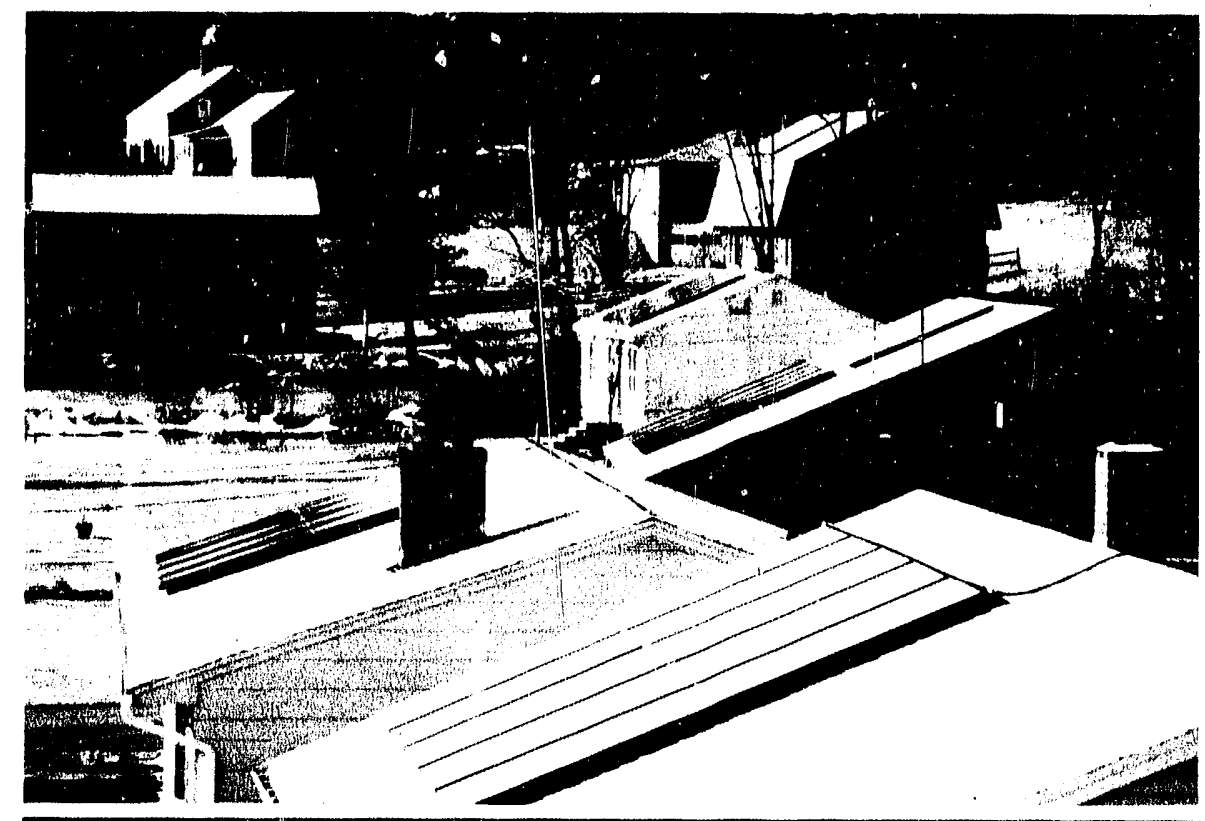

Figure 1-1. PV arrays, each covering 240 square feet of a roof, were installed on each of 30 houses on two neighboring streets in Gardner, Massachusetts. All 30 residences receive electricity from the same substation and are located on one phase of a distribution feeder.
This six-year project has gathered information about the performance, reliability, and cost-effectiveness of residential and commercial photovoltaic systems installed at 38 customer locations. In doing so, we have also recorded variations in electric energy production over long spans of time and have studied the effects of a cluster of PV residential systems on a single distribution feeder. The latter sudy, conducted by New England Power Service Company (NEPSC 0 ) with funding from the Electric Power Research Institute (EPRI), has focused on three areas of greatest potential concern in terms of PV applications: the effects of brief power outages and voltage transients due to lightning and other causes on PV systems and the distribution system; the harmonic performance of inverters and their effect on household appliances, other inverters, and the distribution system; the system effects of fast and slow changes in sunlight, such as those caused by cloud movements.

PV arrays, each covering 240 square feet $\left(\mathrm{ft}^{2}\right)$ of a roof, were installed on each of 30 houses with southern exposures on two neighboring streets in Gardner, Massachusetts, about 50 miles west of Boston. All 30 residences receive electricity from the same substation and 
are located on one phase of a distribution feeder. If the energy provided by the PV system is greater than the energy needed at the site at any given time, the excess energy flows back through the meter to the distribution system. The meter rotates backward as a result of this reverse power flow. Consequently, the customer gets full credit for all of this excess energy.

Most of the homes are 1100$\mathrm{ft}^{2}$ ranches, with an average roof pitch of 23 degrees. No homes have central air conditioning, but 6 of the 30 have window-mounted air-conditioning units . Baseboard electric heat is used in 11 residences. When the study is completed, ownership of the PV systems will be transferred to

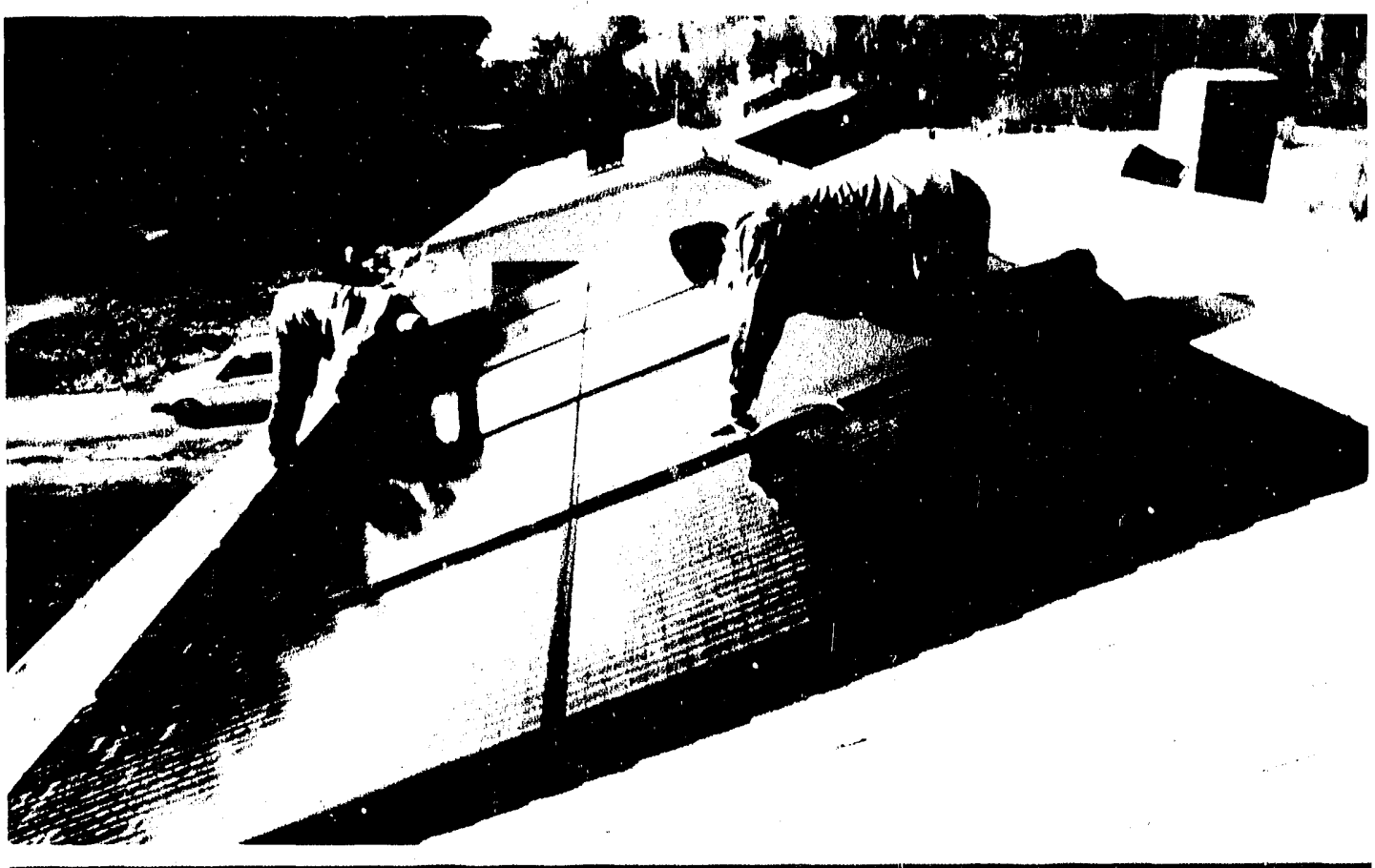

Figure 1-2. The Gardner study has earned a high degree of confidence in PV's system reliability and interaction with the distribution system. Although $53 \%$ of the residential systems have operated on a single feeder, there have been no apparent adverse effects. the homeowners.

The PV systems. The arrays are made of cells of thin crystalline silicon. Measuring 2 inches by 4 inches, these cells were manufactured in Massachusetts by Mobil Solar Energy Corporation. Approximately $11 \%$ of the radiant energy reaching the cells under peak conditions is converted into direct-current (dc) power. The cells are encapsulated in 4 -ft by 6 -ft aluminum modules that can be bolted to the roof. Modules produce 50 volts de ( $\mathrm{Vdc}$ ) and $4.4 \mathrm{amps} \mathrm{dc}$ in bright sunlight at temperatures of $25^{\circ} \mathrm{C}$, which amounts to 220 watts per module.

The modules in each row of five are connected in series, making up what is called a "string," to produce power at approximately $250 \mathrm{Vdc}$. Positive, negative, and ground conductors for both strings are led from the roof down to the basement or garage into a "string combiner," containing surge protection components (metal oxide varistors), string isolation switches, blocking diodes, and a grounding resistor network. The varistors will absorb voltage surges if lightning strikes nearby, but they cannot provide any protection from a direct lightning strike on the PV system.

Completely automatic inverters provide 240 volts alternating-current (Vac) output power. The units disconnect from the house service panel immediately upon loss of utility power, start automatically as soon as sufficient light hits the array, and shut down when insolation falls to an impractical level. The model also has a power-maximizing feature that always optimizes the product of the array's voltage and current. Ten light emitting diodes stacked in a "bar graph" configuration give the customer a reading of power output.

From the electric utility perspective, a major attribute of PV systems is their ability to contribute capacity during summer peak periods. Figure 1-3 (page 4) compares the New England Electric System hourly load profile to the average hourly PV production profile on a day with clear skies. The residential PV systems reach their peak output shortly after the New England System reaches its peak load. Approximately 

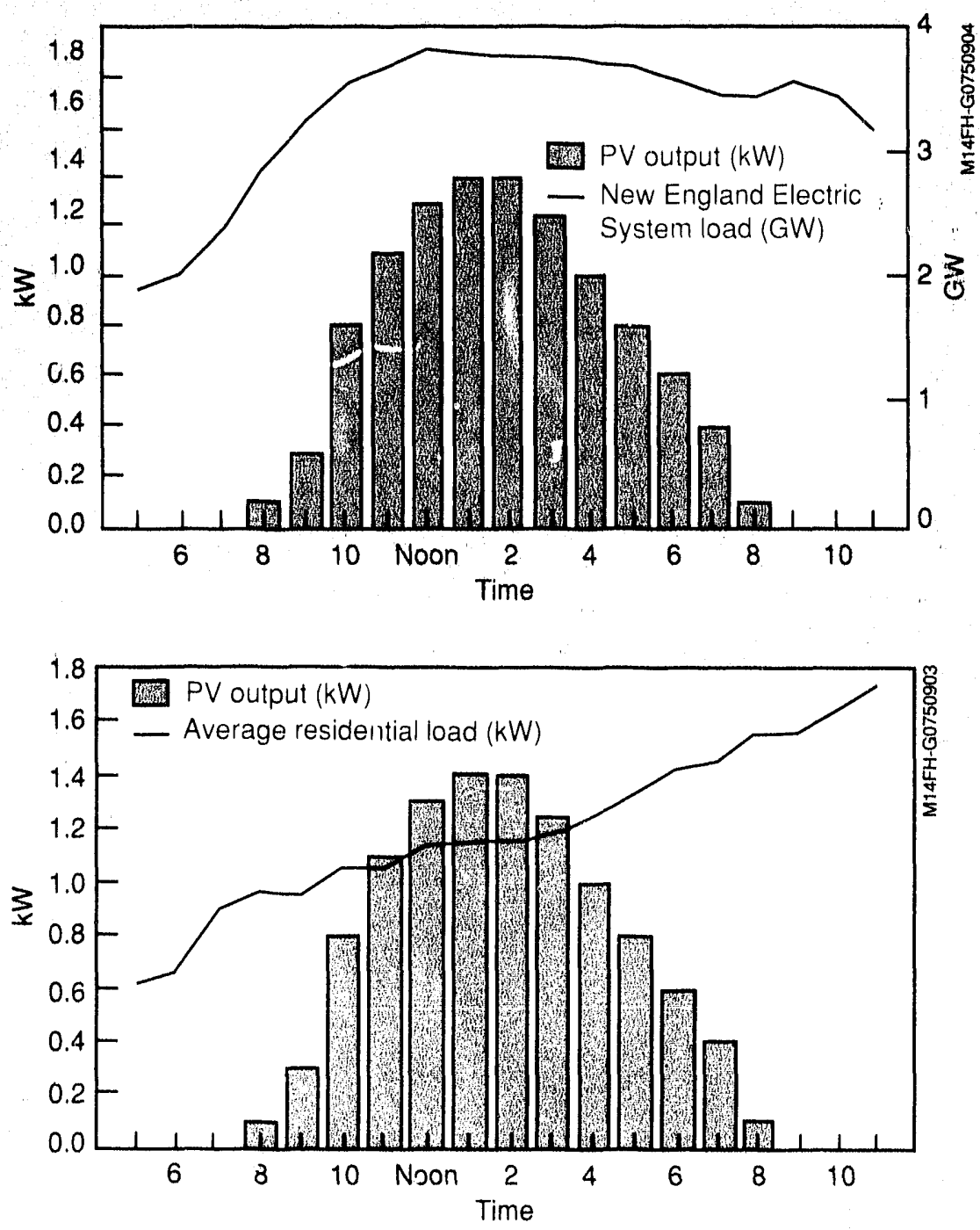

Figure 1-3. This comparison of hourly system load profile to average hourly PV electricity production on a typical clear day shows an attractive complement. Approximately $60 \%$ of the total daily PV output is supplied during the peak period an hourly average of $1.2 \mathrm{~kW}$ of demand reduction during the hours when load is equal to or greater than $95 \%$ of the maximum reached in the day.

Figure 1-4. A comparison of a residential load profile on a typical clear day and the corresponding average PV system profile shows that the PV system supplies all of the home's energy needs on a diversified basis during the hours from 11:00 a.m. to 3:00 p.m. The word diversified is important because each Gardne.r PV system is incapable of meeting any house demand in excess of $2 \mathrm{~kW}$.

60 's of the total daily output from the PV systems is supplied during the peak period, defined as the time when load is equal to or greater than $95 \%$ of the maximum load reached during the day. On an hourly basis, the PV systems provide an average demand reduction of $1.2 \mathrm{~kW}$ during the peak peried.
$P V$ power output. A question frequently asked is, "How much of the home's energy needs can be supplied by the PV system?" The answer is, "None to more than enough, depending on the time of day and the season." Summer is the optimal season for these roof-mounted arrays, because their average tilt angle is 23 degrees from horizontal. Figure 1-4 shows the residential load profile on a typical clear day and the corresponding average PV system profile. From 11:00 a.m. through 3:00 p.m., the PV system supplies all of the house's energy needs on a diversified basis. The word "diversified" is important, because each PV system is incapable of meeting any house demand in excess of $2 \mathrm{~kW}$. It is only because the distribution system acts like a battery, in the energy storage sense, that one phase of the feeder can be considered to be powered by the PV systems on it.

The 30 homes on phase B of the feeder can in fact supply enough energy for 25 other homes without PV systems from noon to 2:00 p.m. on clear summer days. Since rach home uses about $500 \mathrm{kWh}$ per month, and the PV system produces about $270 \mathrm{kWh}$ per month under good conditions, customers have seen reductions of about $50 \%$ in their summer monthly electricity bills.

Figure 1-5 shows the fluctuations in PV production in relation to variations in cloud cover. An index of 0 corresponds to clear skies; days with total cloud cover result in PV production that is, on the average, about $5 \%$ of maximum capability. Daily fluctuations is average PV system output point up the inherently uncertain capacity value of PV systems in the New England climate.

During a three-year span, the typical annual energy production of these systems was $2200 \mathrm{kWh}$. The average monthly output of residential PV systems varies from about $50 \mathrm{kWh}$ in a midwinter month to approximately $270 \mathrm{kWh}$ in a midsummer month. Figure 1-6 shows the average monthly energy production recorded in (iardner from January through Iecember, using three years of data. Winter values are subject to wide variations caused by snow conditions; 
wet snow covers arrays much longer than dry snow, which tends to blow off or melt more readily in sunshine.

It must be noted that the Gardner residences are not oriented to provide maximum solar efficiency. Most are oriented approximately south-southwest at 198 degrees plus or minus 6 degrees. Despite the wide differences in orientation between some houses that face southeast and some that face southwest, average energy production did not vary by more than $1 \%$ during the summer, the most productive season.

PV arrays were also installed on five commercial or institutional buildings in Gardner and at three institutional sites in Rhode Island. The array and powerconditioning configurations were different from those used in the residential study. Since all of these use energy at a considerably higher rate than the PV system capacity, there have been no cases of reverse power flow.

Conclusions. This research has given us a high degree of confidence in photovoltaics, in terms of system reliability and interaction with the distribution system. Although a high concentration $(53 \%)$ of the residential systems has been operating on a single feeder, there have been no apparent adverse effects on the feeder or on the residences served. The total harmonic distortion generated by the inverters is less than the background level observed before the PV systems began operating.

Customer's' acceptance of the systems, in regard to their appearance, operation, and output, has been excellent. The project has also shown that systems can be readily assembled, quickly installed by local roofers and electricians, and easily operated by homeowners.

Moreover, operating both residential and commercial PV systems has brought important benefits to us as a utility. A project like this demonstrates a willingness to explore a source of energy well-liked by the public, with many environmental benefits. Lectures for schools and service groups are just one of the public relations activities that emerged from the project, and the local media have shown a willingness to provide publicity because of strong public interest. And, of course, the knowledge we have gained about impacts of photovoltaics on the distribution system is invaluable. It helps to make a utility ready for the widespread installation of PV systems in the next century. *

Figure 1-5. Fluctuations in PV production during the month of August relate to variations in cloud cover. An index of 0 corresponds to clear skies. Days with total cloud cover result in PV production that is, on average, about $5 \%$ of maximum capacity.

Figure 1-6. Average monthly energy production observed in Gardner, using three years of data. Gardner residences are not oriented to provide maximum solar efficiency; rnost are oriented at 198 degrees plus or minus 6 degrees, approximately south-southwest.
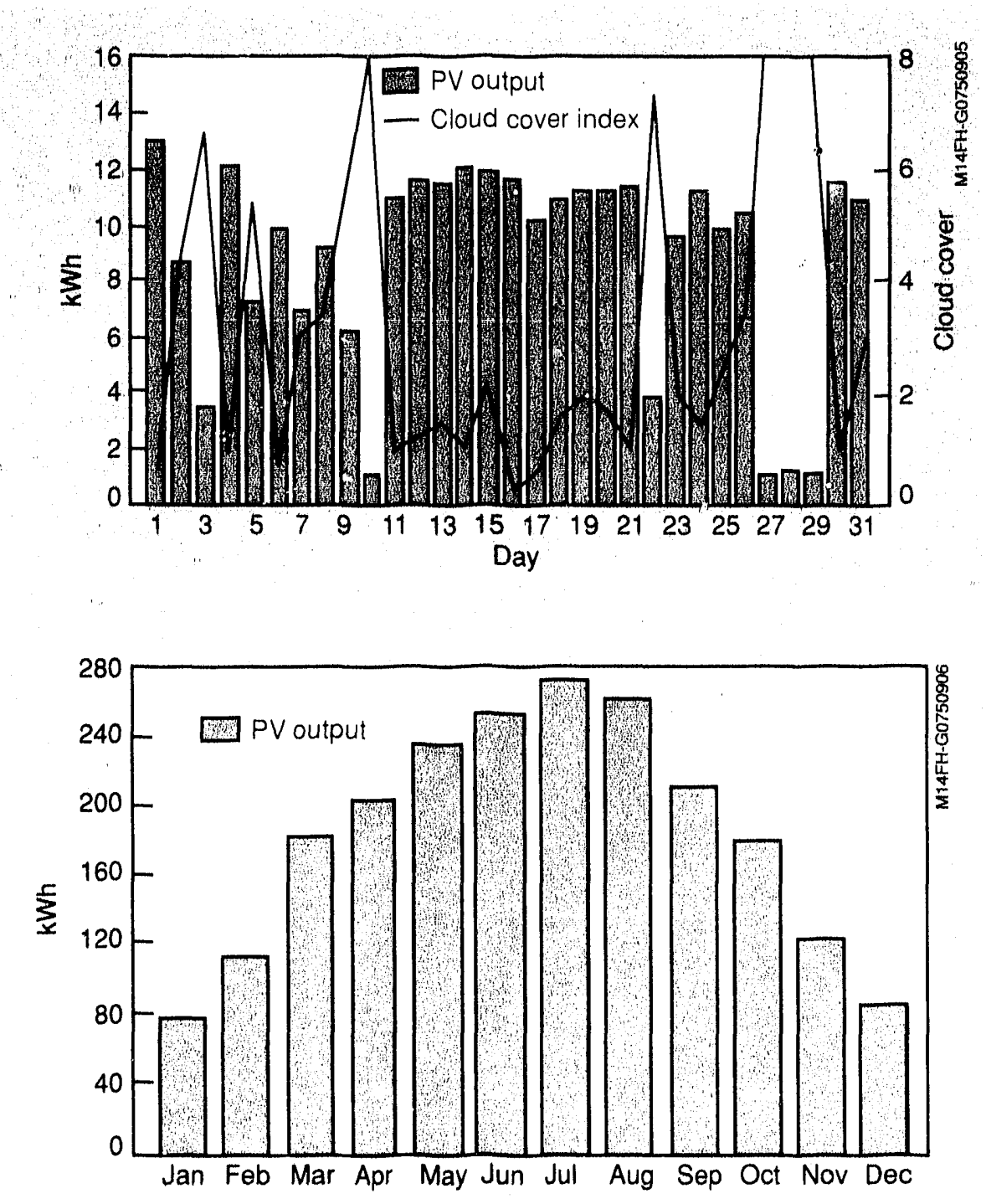


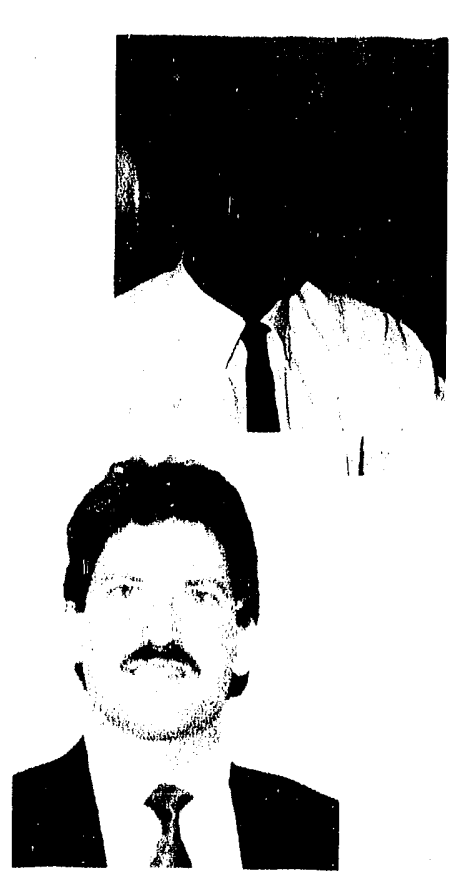

\section{Austin's 300-kW Photovoltaic Power Station:} Evaluating the Breakeven Costs

\section{Austin data gives a realistic portrayal of the competitive position of photovoltaics as an alternative to fossil-fueled plants.}

\section{by John E. Hoffner and David C. Panico* \\ City of Austin Electric Utility Department \\ B year 2001, Austin will require some 125 megawatts (MW) of additional capacity to maintain system reliability and meet long-term demand. At the City of Austin Electric Utility Department, we've adopted an integrated (least-cost) planning approach to minimize costs to our customers. We're now evaluating a wide range of generating options, includ- ing conventional plants, power pur- chases from other utilities, conservation, and alternative energy sources.}

From that possible mix, we've identified photovoltaic electricity generation as an attractive option because of its low maintenance costs, coincidence with utility peak periods, and expected reductions in cell and system costs in the future. Using PV for decentralized applications (at residential and commercial sites throughout the electric service territory) would complement our demand-side management strategy to reduce utility peak demand. Moreover, we've also noticed a healthy interest in renewable resources on the part of our 300,000 customers.

As a result, we have invested some $\$ 3.8$ million in PV demonstration projects to gain hands-on experience, educate and

\footnotetext{
David C. Panico is currently employed by
} Integrated Power Corporation. interact with the local community, and evaluate technical concerns as PV costs continue to decrease. Included has been a study by the Generation Planning Division to evaluate the future (year 2001) value to us of PV generation, quantifying its benefits on the transmission and distribution (T\&D) system and its savings in environmental costs, as well as its traditional energy and capacity benefits. The resulting values have provided us with a range of breakeven costs specific to our service area, and these illustrate the importance of factors other than system cost reductions that justify PV's cost-effectiveness.

Austin's photovoltaic program began in 1986 with the construction of a nominal $300-\mathrm{kW}$ plant known as PV300. Two additional roof-mounted systems, each rated at $1-\mathrm{kW}$, were added in early 1987 so that we could evaluate small resiciontial applications. Results of two years of testing have demonstrated a good coincidence with the electric demand profile, as well as excellent reliability and low maintenance costs. However, the capital costs of grid-connected systems are too high to justify widespread installation here at this'time.

Our value study used conventional generation and transmission planning models, calibrated for the Austin service 
territory and assuming 1990 forecasts for demand and fuel prices. Recent data from the $300-\mathrm{kW}$ single-axis tracking system and from one of the $1-\mathrm{kW}$ fixed systems provided hourly energy production profiles, and these were then adjusted for $100 \%$ availability and scaled up to simulate large, multimegawatt levels of PV generation. In addition, a sensitivity study was performed to factor in the effect of PV plant design (fixed-tilt or single-axis tracking), PV plant size $(25,125$, or $250-\mathrm{MW})$, and the plant type deferred by PV, such as atmospheric fluidized-bed coal (AFBC) or combinedcycle gas turbine units.

\section{Energy and capacity benefits.}

Traditionally, the value of a power plant is based on its energy and capacity benefit. The energy value is the marginal cost of supplying an additional unit of energy (usually greater during highload periods). Capacity value refers to the increase in system reliability realized through a reduction in outages and the deferral of new generating capacity. PV energy and capacity credits were determined by using a planning model called PROSCREEN, which was developed ky Energy Management Associates. Generation expansion plans were calculated for each potential PV plant type and size based on a straight $20 \%$ operating reserve margin, and the resulting capital and production costs were compared with the non-PV base cases. Breakeven costs were then evaluated over a 25-year period.

The PV system sizes were chosen to ensure that the smallest scenario would not defer a full 200-MW coal or gas plant in the year 2001. Thus, the 25-MW plant would achieve only incremental energy benefits, while the two larger 125- and $250-\mathrm{MW}$ plants would result in capacity benefits from deferring a coal or gas plant at least one ycar. The results brought out several important issues:

- Single-axis tracking systems result in a $25 \%$ greater value benefit than fixed-tilt systems.

- Because the 25-MW PV systems were too small to defer future capacity, only the energy value is

reflected, yielding breakeven costs that suggest the great difficulty of justifying PV plants solely on the basis of energy savings.

- The $12 t$ and 250-MW scenarios benefit the utility by deferring the need for future conventional capacity.

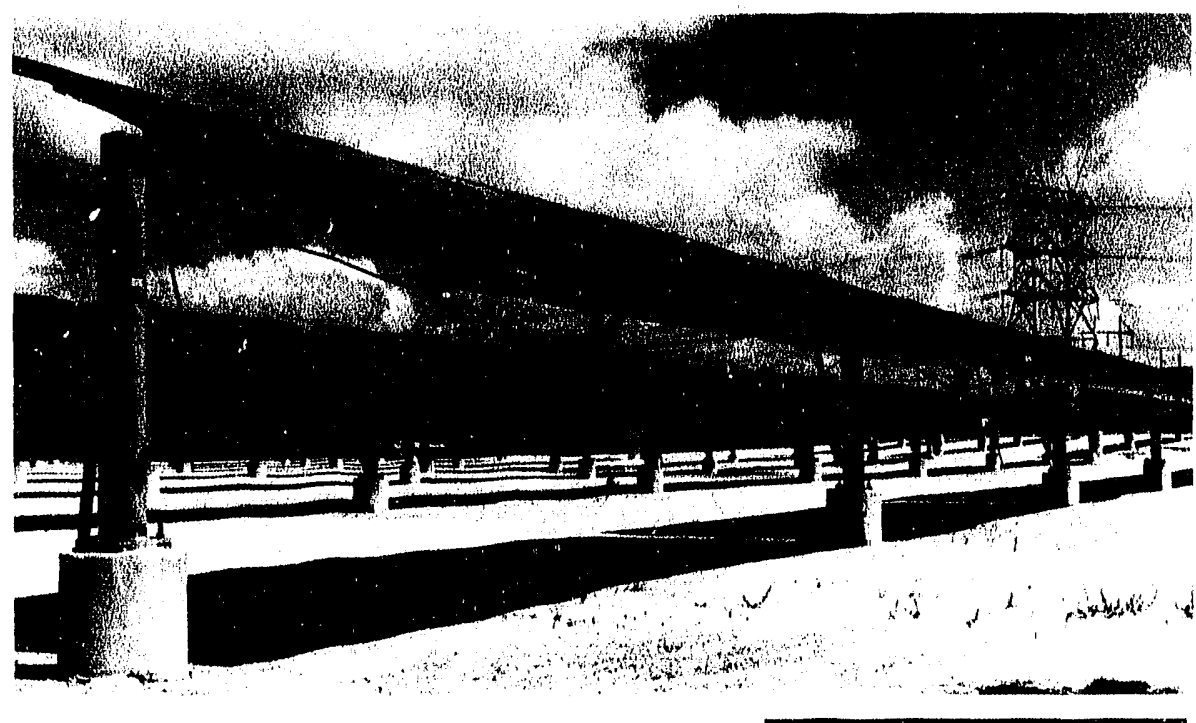

In general, a larger amount of $\mathrm{PV}$ is required to defer generation additions and provide capacity value to a utility. However, there is a diminishing return with large amounts of PV that begin to displace base-load fuel, such as in the 250-MW case.

The results shown in Figure 2-2 (page 8) assumed that all conventional plant additions will be combined-cycle gas turbines. These plants have relatively low capital costs (about $\$ 815 / \mathrm{kW}$ ) and relatively high fuel costs $(\$ 5.27 /$ million Btu, 2001 dollars). To determine the effect of different capital, fuel, and operation and maintenance costs, the analysis was repeated using atmospheric fluidized bed coal plants as the deferred conventional plant type $(\$ 2450 / \mathrm{kW}$ capital, $\$ 2.11 /$ million Btu fuel in 2001).

Figure 2-3 (page 8) illustrates the impact of deferring a high-capital-cost coal plant on the breakeven cost of PV. Note that the value (energy only) for the $25-\mathrm{MW}$ scenario is reduced in the displaced coal case because of lower fuel costs. However, the capacity value is greatly increased, as in the 125- and 250-MW cases.
Figure 2-1. Austin's 300-kW PV plant. (Photo courtesy of John E. Hoffner, City of Austin Electric Utility Department) 
Figure 2-2. Energy and capacity breakeven costs for 2C 1 , showing combined cycle gas turbines, deferred by PV systems.

Figure 2-3. Energy and capacity breakeven costs for 2001, showing fluidized bed coal units versus combined cycle gas turbines, each deferred by single-axis tracking PV plants.
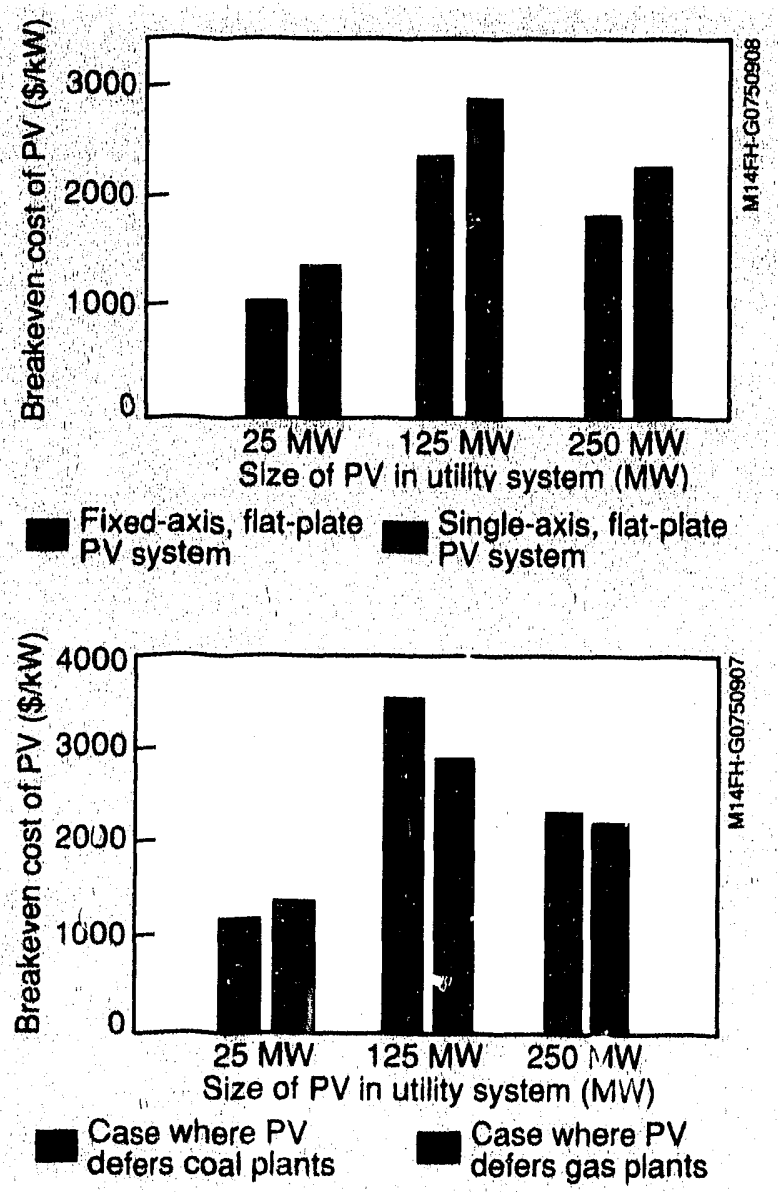

Transmission and distribution benefits $(T \& D)$. An analysis was conducted using calibrated load flow models developed by Austin's Transmission Planning Division to determine the effects of PV on transmission energy losses: The analysis assumed that both central and decentralized single-axis tracking plants would be strategically located throughout the Austin territory in 2001. The results indicate that adding PV would reduce energy losses in the T\&D system during the summer peak hour. If a capacity factor of $22 \%$ is used for the PV plant, and average 2001 fuel costs of $\$ 3.69 / \mathrm{million} \mathrm{Btu}$ (coal and gas), the transmission savings result in 25year cost savings of from $\$ 50$ t» $\$ 58 / \mathrm{k} \mathrm{W}$, depending on the plant size.

Although we did not analyze potential $T \& D$ savings from decentralized $P V$, a conservative estimate would be to double the savings previously noted: from $\$ 100$ to $\$ 116 / \mathrm{kW}$ in reduced losses. Large amounts of decentralized PV would also result in savings from deferring or eliminating the need for future transmission and distribution lines, a benefit beyond the scope of this study.

\section{Environmental} benefits. To factor in PV's environmental benefit from avoiding exhaust emissions, we assumed a future federal credit of $\$ 1500$ per ton of $\mathrm{SO}_{2}$ emissions for new power plants in the year 2000. The performance of $\mathrm{PV}$ in 2001 wass weighed against that of combinedcycle gas turbines or AFBC coal units, considered to be conventional approaches for reducing sulfur dioxide AFBC coal units have been shown to be capable of removing $90 \%$ of $\mathrm{SO}_{2}$ in a coal-firing unit). The total savings projected over a 25 -year period beginning in 2001 translates to $\$ 50 / \mathrm{kW}$ in initial capital costs.

Although no penalties for $\mathrm{CO}_{2}$ emissions are now in effect or under consideration, one projection suggests a penalty of $\$ 15$ per ton or $\$ 0.001 / \mathrm{kWh}$ for new plants that produce significant amounts of $\mathrm{CO}_{2}$. Translating this to a 25-year capital cosi in 2001 results in an additional benefit of $\$ 67 / \mathrm{kW}$ for PV. Moreover, if utilities are required to remove nitrogen oxides with the best available technology (reductions of as much as $75 \%$ are possible using low $\mathrm{NO}_{x}$ burners and reburners, estimated to cost from $\$ 25$ to $\$ 60 / \mathrm{kW}$ in 1989 dollars), PV would provide a cost benefit of $\$ 58 / \mathrm{kW}$. The sum of the projected environmental benefits results in a total of $\$ 175 / \mathrm{kW}$ (2001 dollars). We consider this to be a conservative estimate, of course, that depends on future legislation and on advances in pollution control.

Projected breakeven costs. The total breakeven cost of photovoltaics for a single-axis tracking system in Austin in the year 2001 ranges from $\$ 876$ to $\$ 3885 / \mathrm{kW}$, depending on system size, the type of traditional plant deferred, environmental constraints, future fuel costs, and plant design. Not included are possible savings from the deferral of new T\&D lines. $\%$

\section{Acknowledgments}

We would like to thank the other member's of the study team that helped carry out the detailed analyses: The Generation Planning Division, particularly Leeways De La Rosa, Joseph Lauer, and Mark Becker; and Scott Helyer, Rick Scadden, and Judith Clarkson, all with the City of Austin Electric Utility Department. 


\section{Residential Photovoltaics:}

\section{The Lessons Learned}

\section{San Diego utility taps 2000 MW of photovoltaic resource for a safe, reliable demonstration on "free land."}

\begin{abstract}
San Diego Gas and Electric Company (SDG\&E) has been interested in rooftop residential PV systems as a potential energy resource since the eirly 1980s. It has been estimated that more than $2000 \mathrm{MW}$ of photovoltaic resource exist on south-facing roofs of moderately priced or higher priced homes in the San Diego metropolitan area.
\end{abstract}

From our standpoint, this rooftop area is the equivalent of "free land" for photovoltaic generation: it needs no development, environmental impact statements, or extensions of transmission lines. Moreover, when our customers are offered an appropriate package containing PV system costs, conventional energy costs and rate design, and tax breaks or other incentives, we anticipate that many would be likely to participate in a well-planned, residential PV power program.

We had a number of inducements to pursue PV and other power-generation alternatives during what was a relatively early stage in the development of these technologies. Since SDG\&E is a sun merpeaking utility, with annual peaks usually occurring on clear summer afternoons, the match with PV system output is excellent. It stands to reason that the sun's energy during this time should be converted from an enemy tri an ally.

During the early 1980 s, before the oil glut occurred and our rates began to

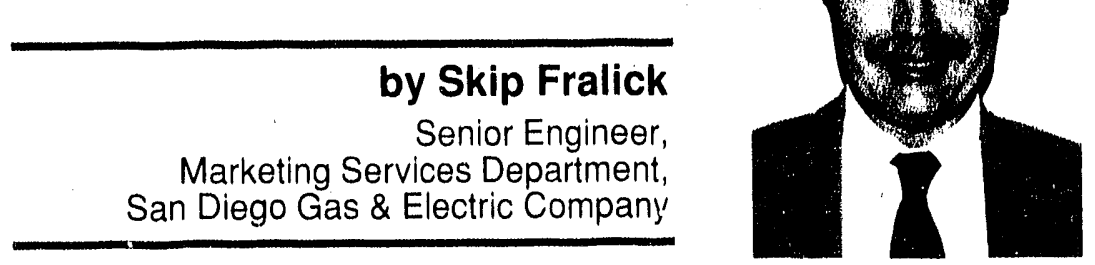

decrease, there were indications that San Diego might see a large PV market develop in a relatively short period of time. PV would not have offered a costeffective alternative to fossil-fuel power plants, as determined by conventional least-cost planning. But we were motivated to test the interconnection standards and procedures that would accompany PV's integration into the grid.

Specifically, we wanted to gain experience in the coliective impacts of residential PV on a feeder, in terms of power quality and safety. As a result, and in addition to our participation with the Institute of Electrical and Electronics Engineers' (IEEE) PV Working Group and the Electric Power Research Institute, we interconnected a 36-unit townhome development with r.oftop PV collectors in 1986.

Each home at the Laguna del Mar development featured a $1-\mathrm{kW}$ (directcurrent) system, employing 27 singlecrystal silicon modules and a highfrequency self-commutated inverter. Systems were installed by the developer and were owned by the customer as an inclusion in the new home. Each had a dual meter, connected in series, to record electricity flowing from and to the grid. Electricity was sold back to us at its retaii cost. Assuming the typical case in which the customer's monthly kilowatthour ( $\mathrm{kWh}$ ) purchases from SDG\&E

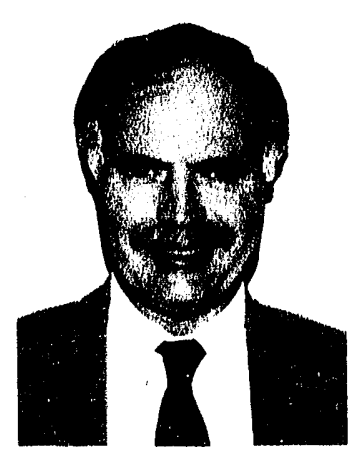




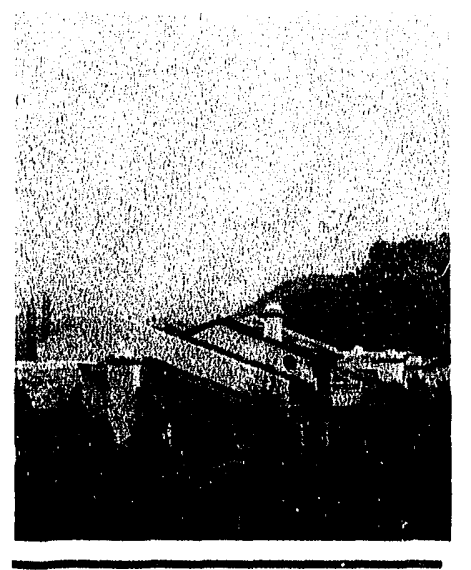

Figure 3-1. Rooftops in the Laguna del Mar development in San Diego, California provide "free land" for photovoltaic generation. exceeded the $\mathrm{kWh}$ fed back to the grid, our grid acted, in effect, as free storage for the customer's excess PV production.

Typical peak output during summer afternoons was 700 to 800 watts alternating current per system, benefiting our summer coincident demand. Typical monthly energy production was around $120 \mathrm{kWh}$; about half that total went to each home and half to SDG\&E's grid. The collective output made no contribution to our winter peak period ( 5 p.m. to 8 p.m., October through April).

As a result of that experiment, $S D G \& E$ achieved a wealth of experience in working with photovoltaics that will benefit us as the decreasing cost of PV makes various grid applications more attractive. We also discovered some problem areas needing attention. A summary of our experiences follows.

Power quality. A low rated system voltage (48 volts) for each PV system allowed the developer to use a lower cost inverter and avoid additional building code issues that would have been met with a higher rated system. However, we had concerns about the possibility of high levels of harmonics being created by the PV systems, especially by the lower cost inverter. Fortunately, our monitoring in limited testing showed no power quality problems.

"Islanding" or "run-on." We also had a major safety concern, one that probably mirrors the concern many utilities have in getting involved with customerside systems. We feared that in case of a power outage, the PV system inverters might continue "talking" to each other and "fool" each other into continued electricity production, thereby jeopardizing the safety of our repair staff.

This did not develop into a problem. Our requirement that customer-side PV inverters shut down when utility power is lost was met throughout; we had no reported incidents of failure to comply. (See "The Issues of UtilityIntertied Photovoltaics," by John Stevens, page 23, for a more detailed preliminary assessment of those risks.)

\section{Interconnection procedures.}

Procedural matters concerning customer economics and demands on utility personnel's time became very important during the test. Although we had standard interconnection agreements available based on the Public Utilities Regulatory Policies Act, these had to be simplified and clarified to ensure that the energy "sellback" agreement with SDG\&E was not interpreted as a commercial arrangement. This was both to protect the homeowner from income tax liability and to ensure that a liability insurance requirement of $\$ 100,000$ per home or system could be handled by standard homeowners' policies.

We learned quickly that few insurance companies understood FV systems or were aware of their relative safely. (To our knowledge, no serious accidents or fatalities have occurred with residential PV systems.) As a result, both the developer and SDG\&E had to educate many insurance brokers about the operation of a new technology.

Results and recommendations. From a technical standpoint, we were pleased to find these customer PV systems to be relatively benign with respect to our power quality and safety concerns. However, much needs to be done to streamline interconnection procedures and insurance requirements before gridconnected PV systems can be offered to large numbers of customers. Attention needs to be given to allowing standardized system drawings to facilitate technical review. Work also needs to be done to persuade insurance companies to include liability insurance under standard homeowners' policies. Perhaps most importantly, utility managers and regulators need to work toward modifying or eliminating the array of bureaucratic barriers that siand in the way of novel utility-customer arrangements-barriers that may be as detrimental to $\mathrm{PV}$ power as the actual economics themselves. $*$ 


\section{Photovoltaics for Electric Utility Use \\ Utilities are making a significant attempt to understand PV's potential for electric power applications - from a few watts to several megawatts.}

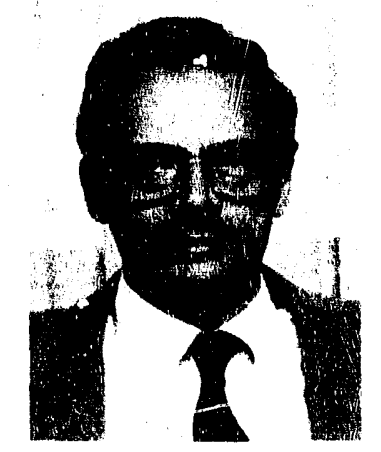

O ver the past 15 years, the world has invested some $\$ 5$ billion in developing renewable power technologies. Prospects for these are now relatively clear, and of the few that continue to be pursued with vigor for energy-significant power applications, photovoltaics has developed the broadest base of support.

PV's attributes include its high modularity, simplicity, low operating and maintenance costs, environmental acceptability, and suitability for a wide range of applications. A sizable development community is now pursuing PV (increasingly with corporate funds) and technical advances continue unabated.

The basic energy efficiency of PV "solar cells" has been steadily increasing.

Small-area tandem thin-film cells have exceeded $15 \%$ efficiency, and single-layer concentrating cells are nearing $30 \%$.

Both show potential for acceptable costs in large-scale production. Advanced tandem concentrator cells for space applications have been reported at $37 \%$ conversion efficiency.

A decade ago, the major uncertainties associated with PV's advancement were primarily technical. Now it seems virtually certain that, given continued at tention to cell research, manufacturing development, and value engineering, expectations for at least one and perhaps a number of PV cell technologies will be fulfilled, raising new questions concerning the translation of technology into

\section{by E. A. DeMeo \\ Manager \\ Solar Power Program,} Electric Power Research Institute

new market products, first for remote power and then for the electric power industry.

The utility industry is now making a significant attempt to understand PV's potential for electric puwer applications through resource assessments, smallscale testing, and detailed comparisons of PV module and array types. Meanwhile, a major cooperative field test, Photovoltaics for Utility-Scale Applications (PVUSA), is under way in Davis, Calif., spearheaded by Pacific Gas \& Electric Company and co-sponsored by the U.S. Department of Energy, Electric Power Research Institute (EPRI), the California Energy Commission, and several other utilities and agencies. Objectives are to serve as a test bed for emerging module technologies, to provide utility operating experience with utility-scalable segments, and to foster balance-of-systems innovations to reduce costs and relax design and construction requirements.

The megawatt-scale plants have demonstrated that PV power systems using state-of-the-art, single-crystal technology operate safely and reliably with performance close to predictions. They have provided conclusive demonstrations of modularity and short construction times, and the operating and maintenance experience in ruatine operation bodes well for attractively li,w operation and maintenance costs. The significance of these developments is now beyond 
Figure 4-1. A decade ago most of the uncertainties associated with PV were primarily technical. Now, through research efforts such as the PVUSA field tests of promising module technologies, expectations for perhaps a number of cell technologies will be fulfilled. (Photo courtesy of Hawaiian Electric)

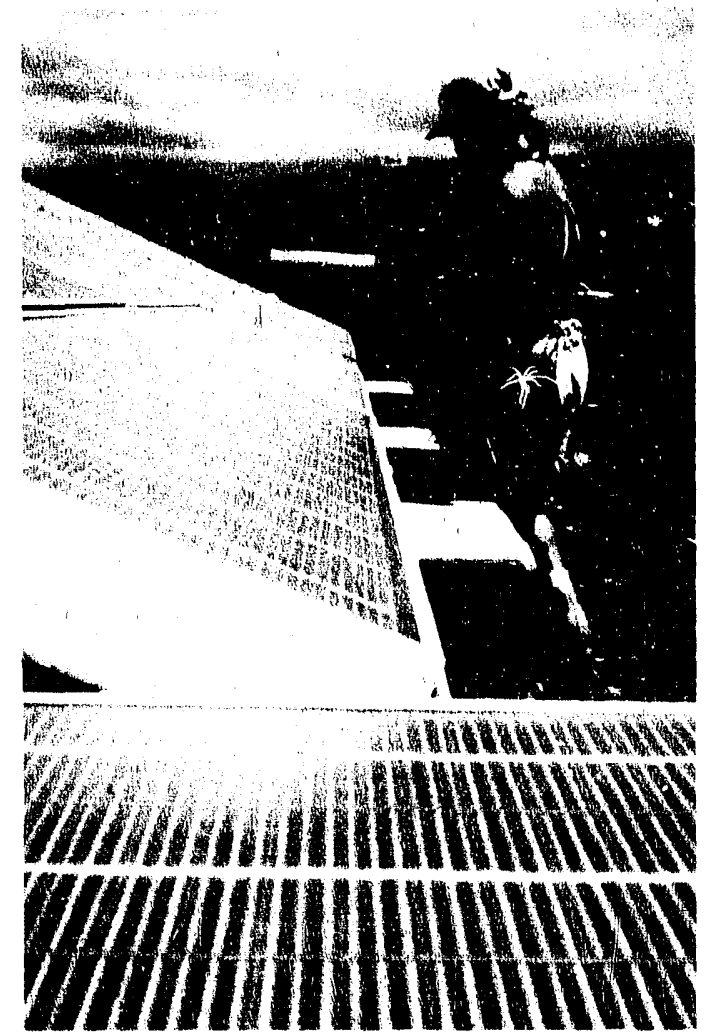

doubt: today's PV power technology and associated power-conditioning apparatus are technically viable in electric utility applications.

Applications. Utility companies are beginning to use PV in remote power applications, ranging from a few watts for automated meters to a few thousand watts for cathodic protection. Although total capacity is relatively small, the significance of these should not be underestimated. First, PV was the system of economic choice for these applications. In cases such as perimeter lighting and transmission tower beacons, great quantities of grid power are available nearby but the costs of cable trenches or stepdown transformers far exceed the cost of the PV system. Meanwhile, these systems are achieving credibility in the eyes of utility engineers, for whom reliable service is paramount.

Utilities are also becoming more involved with consumer-owned, line-connected PV systems, including some 200 residentialsize systems. A particularly useful experiment involving 30 homes on a single distribution feeder has been conducted by the Now Fingland Electric Syetem? over the past several years ( see "Residential Photovoltaics: The New England Experience Builds Confidence in PV," by John Bzura, page 2). The results of the impact analysis indicated no significant negative impacts, while a surprisingly good correlation was observed between electrical demand and PV array output.

Economics. Of course, economics is the ultimate driver affecting the penetration of PV into the energy supply system. In the long run, bulk power competitiveness, whether in distribution-feedersized systems of hundreds of kilowatts or larger megawatt-scale systems, will require substantial reductions from today's PV costs. EPRI believes that a cost of $6 \&$ to $8 \& / \mathrm{kWh}$ (1990 constant dollars) for PV electricity is required for significant bulk power use, without special tax or incentive considerations and assuming current projections for conventional fuel costs during the mid1990s. Corresponding total installed costs for PV systems in areas with high sunlight availability are in the range of $\$ 1500$ to $\$ 2000 / \mathrm{kW}$

Achieving these cost goals will require further advances in research, engineering and business development; early power plant installations will probably require partnerships between equipment suppliers and user's with commitment.s that go beyond the traditional buyerseller relationship. Several utilities have already formed business ventures with PV industry members; the PVUSA project and other alliances involving EPRI and individual utilities represent important steps in this direction.

Public interest. Motives other than those purely economic are becoming increasingly important in considering PV applications. Public interest was the primary force behind utility attention to solar and wind power following the 1973 oil embargo. The strength of this incentive has since decreased, owing to fossil-fuel price reductions and to the realization that many expectations of the 1970s were unrealistic. But the public appeal of solar power is still very much alive, and a resurgence of popular support is now occurring. 
Society, and utility organizations as responsible members of society, are becoming increasingly concerned about the impacts of large-scale power generation on the environment. While issues such as detrimental emissions and global warming through greenhouse gases, as well as the specific contributions made by electric power generation, are not well understood, there is mounting evidence of damaging impacts. The length of time required to obtain definitive answer's will probably be measured in decades.

It is unlikely that society can wait, since the time for corrective action may be long past when resolution is finally achieved. Legislators seem to be reaching similar conclusions, so it is probable that incertives for renewable energy will be enacted in the United States in the near future.

Future concerns. While EPRI has not. performed any comprehensive projection of bulk power market size and penetration for PV power technology, we have conducted sufficient analyses to convince us that the market opportunity for PV through the 1990s exceeds by a wide margin the PV industry supply capability. For example, data on generationaddition plans and load forecasts in the southwestern United States indicate a market of some 40 gigawatts (GW) for new generating capacity of all types through the year 2000. If one assumes that $10 \%$ to $20 \%$ of this total is combustion turbine capacity, and that PV can capture one-fifth of that market, then the resulting opportunity for PV is in the neighborhood of' $1 \mathrm{GW}$. An annual breakdown suggests a corresponding market of 100 to $200 \mathrm{MW}$ per year by the late 1990s in the Southwest. This estimate is judged to be conservative since (a) it is based on modest load growth projections; (b) no real escalation of fuel costs is assumed; (c) no disruptions in fuel supply are assumed.

As research brings the technological costs down, what other limits will be faced? In areas of the United States with good solar resources, the availability of land for PV power plants is simply not an issue. Mature solar power technology is expected to generate approximately $100 \mathrm{MW}$ per square mile, an amount comparable to coal power plants when the coal mining area is included. Moreover, land cost does not significantly affect the toial cost of solar plants until land prices approach $\$ 50,000$ per acre. At this price, one square mile (640 acres) would cost $\$ 32$ million or about $15 \%$ of the expected cost of a $100 \mathrm{MW}$ plant using mature technology. In southwestern deser't regions of the United States, there are many areas that could easily allow hundreds of gigawatts of solar power production.

The intermittent nature of sunlight sets a far more significant constraint on penetration of PV into the power supply network. Even in areas of high correlation between utility peak loads and sunlight availability, PV cannot support the baseload requirements that remain after peak loads are served. Further penetration will require available storage and/or fuel production from the solar electricity. There is already great incentive for' utilities to develop economical storage,

Figure 4-2. Large-scale demonstrations by the utility industry have shown that $P V$ power systems using single-crystal technology operate safely and reliably, with added benefits of modularity and short construction times. Maintenance experience in routine operation bodes well for low O\&M costs. (Photo courtesy of Mobil Solar Energy Corporation)

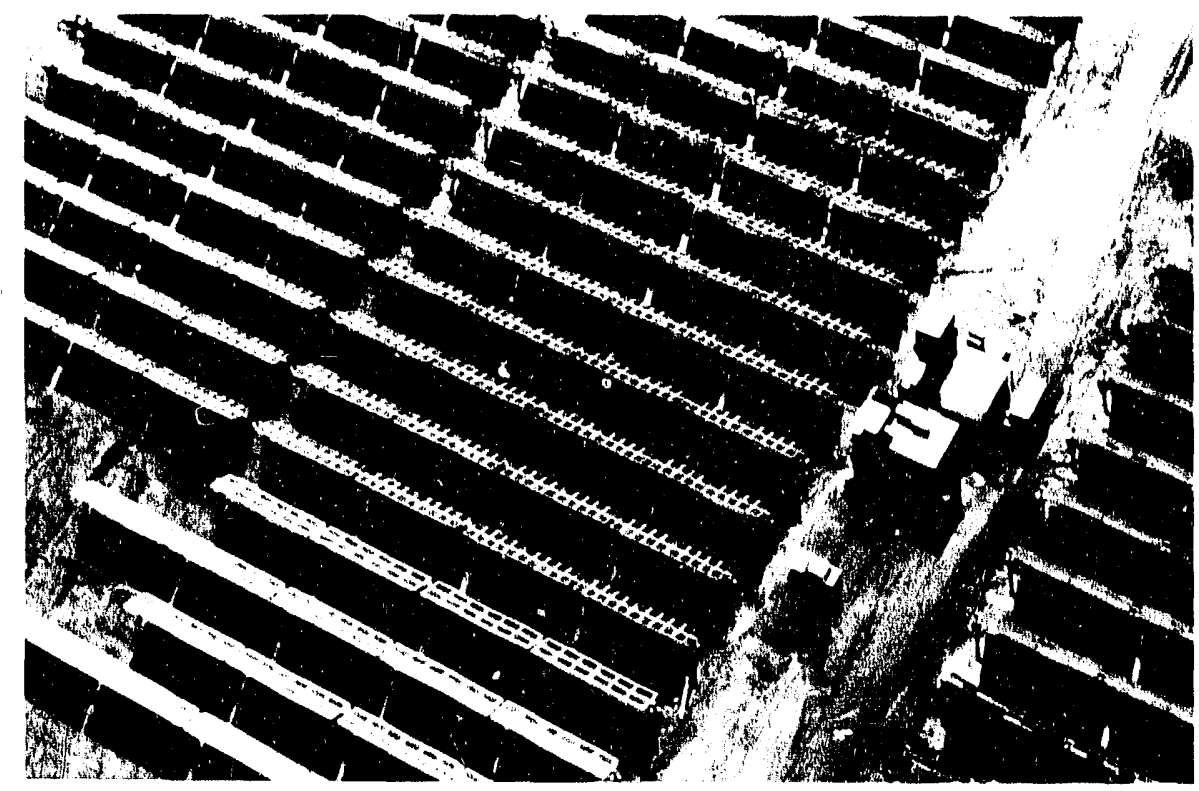




\section{PVUSA-A Test Bed for Utility-Scale Photovoltaics}

PVUSA is already evaluating emerging PV module

technologies at its test sites near Davis, California and on the island of Maui.
Utility industry and government researchers have already developed an effective vantage point for viewing the progress of $P V$ technologies. Photovoltaics for Utility-Scale Applications (PVUSA) is a national cooperative research project spearheaded by Pacific Gas \& Electric, that involves the U.S. Department of Energy, the California Energy Commission, Electric Power Research Institute (EPRI), and various regional utilities.

With extensive technical review provided by Sandia National Laboratories, the Solar L nergy Research Institute, Jet Propulsion Laboratory, EPRI and others, PVUSA is already installing and operating photovoltaic systems at a large site in Davis, Calif. One phase of PVUSA's mis sion involves evaluation of "emerging module technologies." Small arrays, representing specific PV cell designs nominally sized at $20 \mathrm{~kW}$ each, are currently being tested. $A$ variety of promising modules, including arrays of microgridded crystalline silicon, amorphous silicon, polycrystalline silicon and various "thin film" cells, are already on line.

Meanwhile, PVUSA is installing larger arrays $(200 \mathrm{~kW}$ to $400 \mathrm{~kW})$, representing more mature cell module technologies, with the aim of demonstrating systems capable of being turned over to utilities for operational service. PVUSA is also working to create an information iransfer program to share knowledge with utility and other energy professionals.

\section{5)}

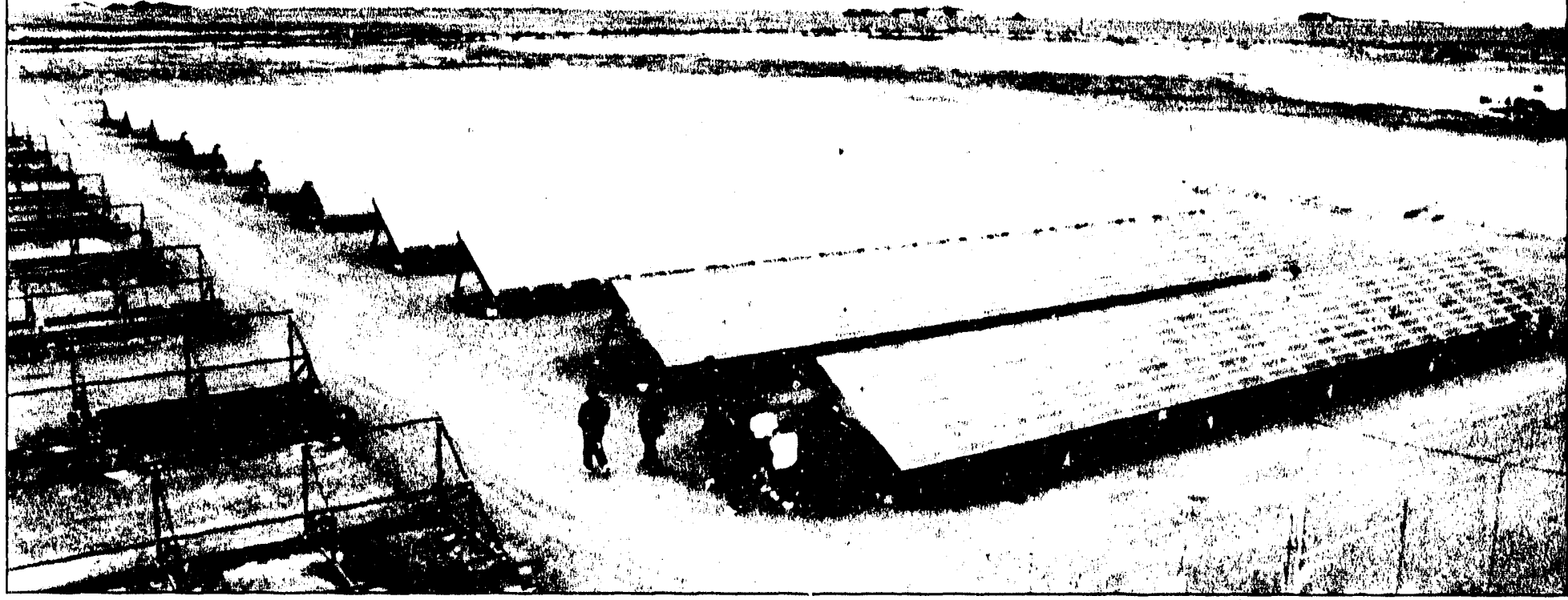

both for enowating flexibility and lore peak load shasing. Tou tho same estont

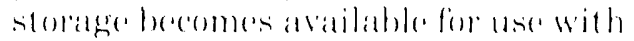

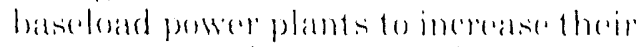

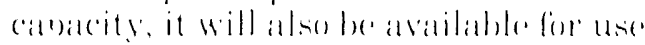
with informitent remewahle powere

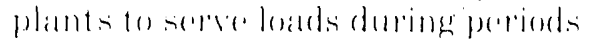

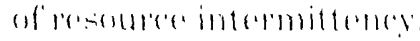

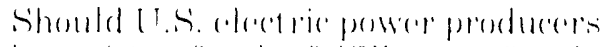

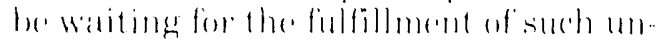

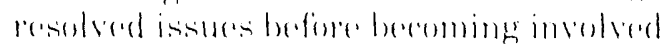
in P'applicattoms.' 'Thatt's a call that

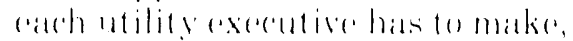

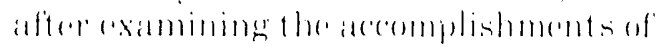

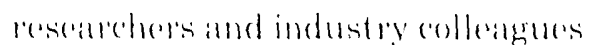
during the last fow yoats. Howererer, he prepand to be implessed hy the reliahility and viablity that rivis domomstratting in utility applications.

It is likely that dotilites and thoir

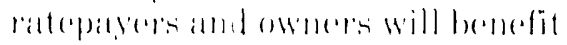

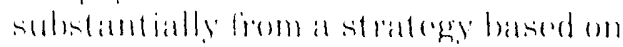

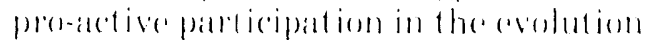

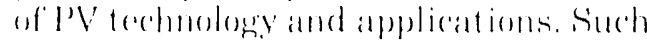
a strategy will maximize the soredelal

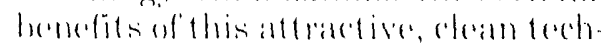

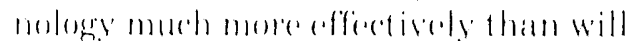

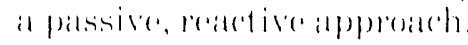




\title{
Least-Cost Planning: The Environmental Link
}

\section{Environmental impact costs are raising utility rates - and beginning to play a part in least-cost planning.}

\author{
by Henry G. Williams \\ Commissioner, New York State \\ Public Service Commission
}

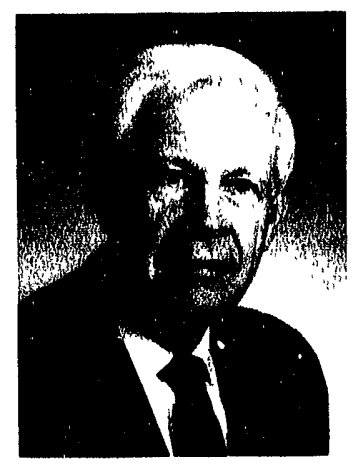

$\mathbf{R}$ Association of Regulatory Utility Commissioners (NARUC), utility planness, and others have brought to light significant relationships among leastcost utility planning, environmental externalities, and renewable energy technologies. Although the principles underlying each of these subjects have been developed over many years, general ideas are now being shaped into specific policies and actions.

Several state regulatory bodies have now adopted a variety of measures that would enable utilities to realize leastcost plans as their most profitable courses of action. New England Electric Company has begun to consider environmental externalities in its long-range planning process, and NARUC has conducted a seminar to address public policy questions pertaining to relationships between regulation and renewable energy technologies.

These activities have demonstrated that least-cost, e ternalities, and renewables are complex subjects that involve sophisticated technological and economic investigations and often lead to different interpretations of results. It is not surprising, then, that some regulators and managers of utilities envision opportunities and gains for society in these links, while others see only problems and losses.

In preparing least-cost plans, utility planners normally consider price, reliability, and operational flexibility in providing for the most efficient way to satisfy future energy needs. Following such a conventional approach, a fossil-fuel powered generation facility would normally be chosen over a photovoltaic facility even though the fossil-fueled plant might result in greater adverse environmental impacts.

This practice of choosing electric resources based on conventional cost and reliability considerations resulted in designs for fossil and nuclear power plants that barely met minimum legal requirements. It was not until the 1970s that heightened public concern about environmental damages from discharges of air and water pollutants and the disposal of hazardous waste prompted tougher environmental laws and regulations and greater attention to alternative energy technologies.

Today's power plants are subject to increasingly stringent federal and state environmental regulations. The new Clean Air Act will impose additional requirements on many of these plants, particularly in terms of the rules requiring significant reductions in sulfur dioxide emissions. The costs associated
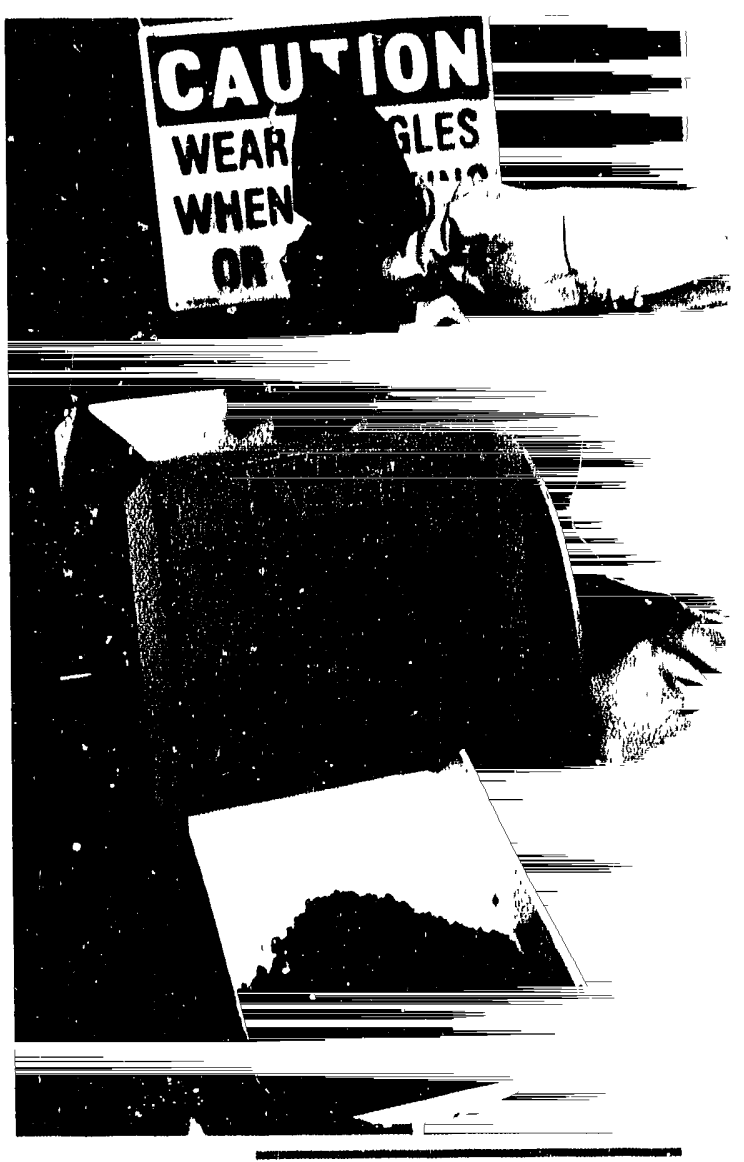

Figure 5-1. PV modules have been ground and tested for possible toxicity. They have been classified by EPA testing methods as ordinary (non-toxic) material. 


\section{Photovoltaics Are Already Cost-Effective for Some Applications}

The promise of PV systems for utility applications is bolstered by the fact that photovoltaics is already the technology of choice for hundreds of installations, based on cost alone and with no credit applied for environmental or other considerations.

Cathodic protection powered by PV. (Photo courtesy of Pacific Gas \& Electric)

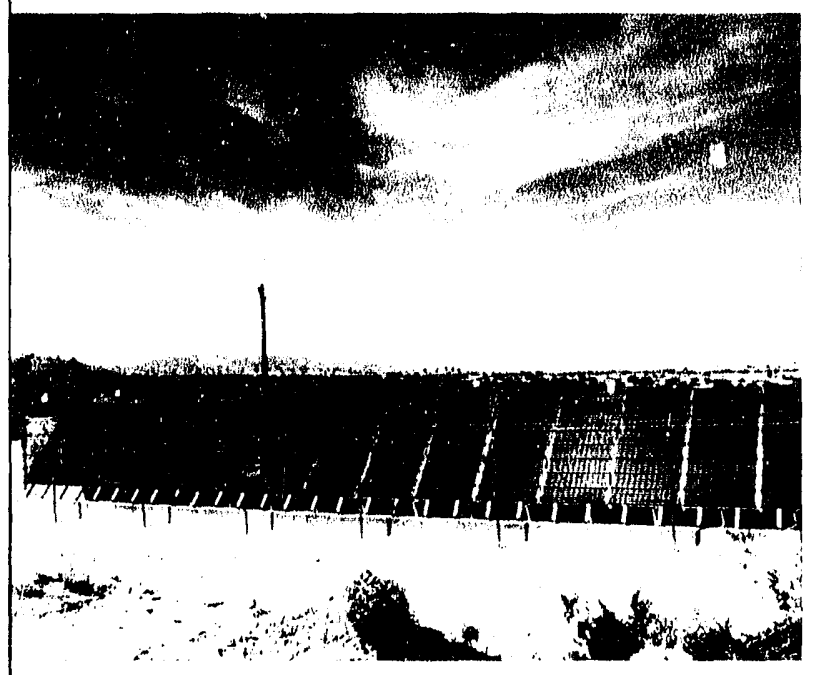

Although these costeffective uses are overwhelmingly stand-alone systems, they are not necessarily remote applications. The following applications are among those that have been implemented in specific Pacific Gas and Electric locations: gas flow computers, water level sensors, automated gas meters, meteorological towers, microwave repeaters, warning sirens and aircraft beacons, hydro gatehouses, backup generator starters, water temperature sensors, and cathodic protection systems.

Typical factors that invite a comparison with the PV alternative include situations where the cost of building and maintaining distribution lines is out of proportion to the size of the installation, or where the cost of fueling and maintaining an on-site generator is required. According to PG\&E, problems that have been encountered with $P V$ installations, including theft and vandalism at remote sites and failure to properly scale a system for load and local weather conditions, are usually quickly remedied.

Cost-effective PV systems carry another benefit back to the utility, as well: they help acquaint engineers and line staff with a technology that will become increasingly important in the company's future.

To learn more about PG\&E's experience with costeffective systems, see Additional Information, page 31 , author $\mathrm{C}$. Jennings. with these envirommental repuirements will moan that plants once considered least-cost choices will ond up as more exponsive options for ratepayorts.

Many regualatory bodies and utilitios now anderstand that longrerange cost plojere tions cannot be made without carrefial comsideration of all the foresereable onvirommental costs of powere groncration. 'This now kind ol' thinking has lod somor state lowulatery hodics to guantify the

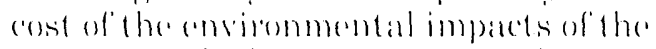

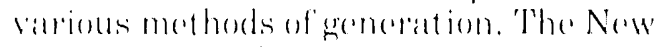

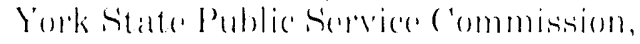
for instance, has identified the emsiremmontal imparets of a mew, base ford coalfired plant that moets ('merent minimum legal reguidements: the cemmission has estimated the cosit of these imparets at $1.1 \mathrm{kWh}$.

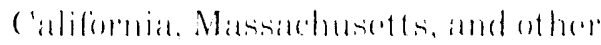

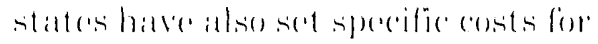
(rovirommontal imparts. In thesestalles the envirommental impacts of new oncergy projects will be chareged to theip production cost to compare the cost of altermative energy resoureess. This process. which would increase the cost of power gerencerted hy fossil fucls, would permit energy projects that ane relatively more bonigen in torms of (nnvironmental impacts such ats photovoltaics, to win overe fossil-fual projects in ermpetitive bideling sitnations.

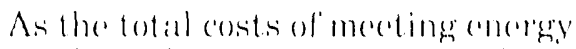

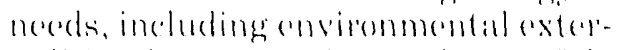
malitios, hecome an integral part of the

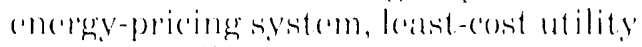
phanning will allow remowahle allergy

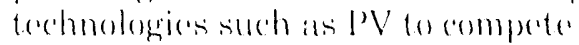
offeretively with fossil fuels. 'Thre compotitivestrengthof photosoltates would be

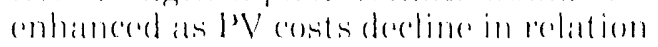

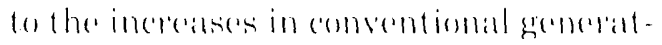
ing costs that result firom the greserter

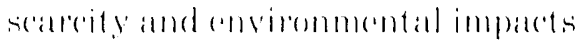
assocolated with fossil later. 


\section{Photovoltaics in the Distribution System}

\section{Computer modeling suggests that small photovoltaic plants can be a cost-effective choice in solving T\&D overload.}

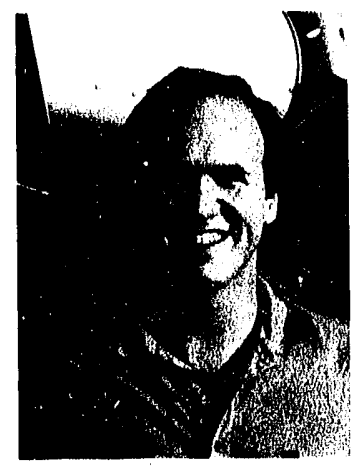

\begin{abstract}
A - tmidday, when PV is typically generating maximum power, utility loads are often at peak levels. The basic compatibility of photovoltaics for utility applications lies not just in PV's dependability and environmental benefits, but also in the way the hourly generation curve of a PV plant overlaps the demand curve experienced in many service areas.
\end{abstract}

In addition to the potential for central station power plants, this basic compatibility opens a near-term role for distributed grid-connected photovoltaic generation in select transmission and distribution systems, as a remedy for transmission and distribution (T\&D) overloading. Pacific Gas \& Electric (PG\&E) has investigated this possibility and found that PV may already be a cost-effective alternative.

The PG\&E study was designed to evaluate strategically sited PV installations to reduce thermal overloads of distribution lines and transformers. These are typically corrected by reconductoring lines, upgrading the transformer bank, or adding an additional circuit. In selecting a test site, we sought locations where PV output would correlate with the distribution peak load, where load growth would be slow, and where there was sufficient land area 110 acres I for constructing a PV plant. The search was kept manageable by limiting choices to PG\&E's San Joaquin Valley region.

PG\&E predicted the effect of a simulated 50)-kW PV plant on the load of each

\section{by Daniel S. Shugar \\ Department of Research and Development, \\ Pacific Gas \& Electric Company}

feeder in the region for every hour of 1989. Hourly feeder loads were developed from actual billing data (the load for the selected feeder is shown in Figure 6-1), and the simulated output of the PV plant was modeled using solar resource data and performance equations. The PV system chosen for output and cost comparisons uses flat-plate modules mounted on single-axis trackers. The tracking axis is horizontal, and oriented in a north-south direction. Two inverters were chosen that would provide a unity

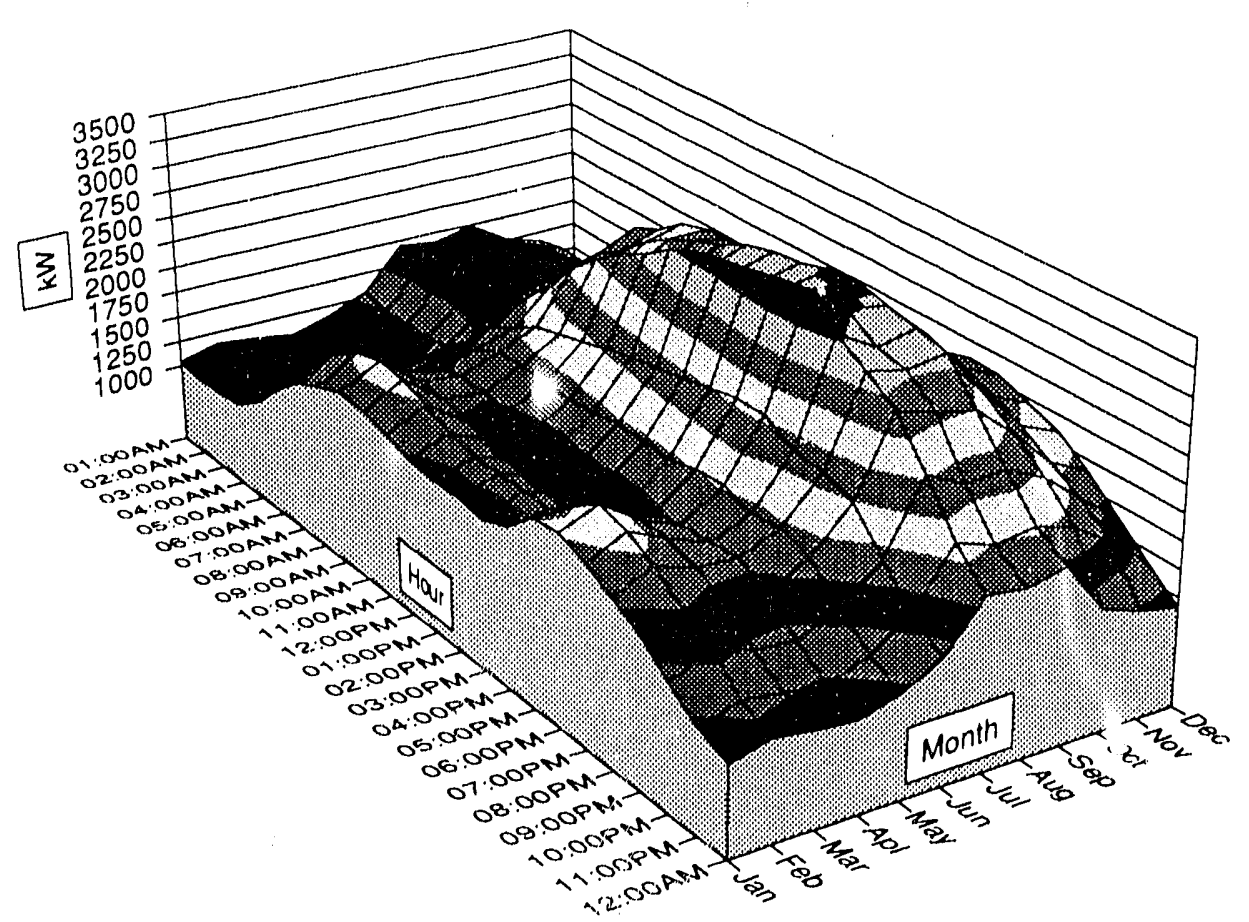
shows the average hourly loads for a feeder in California's San Joaquin Valley.
Figure 6-1. Computer graphic 

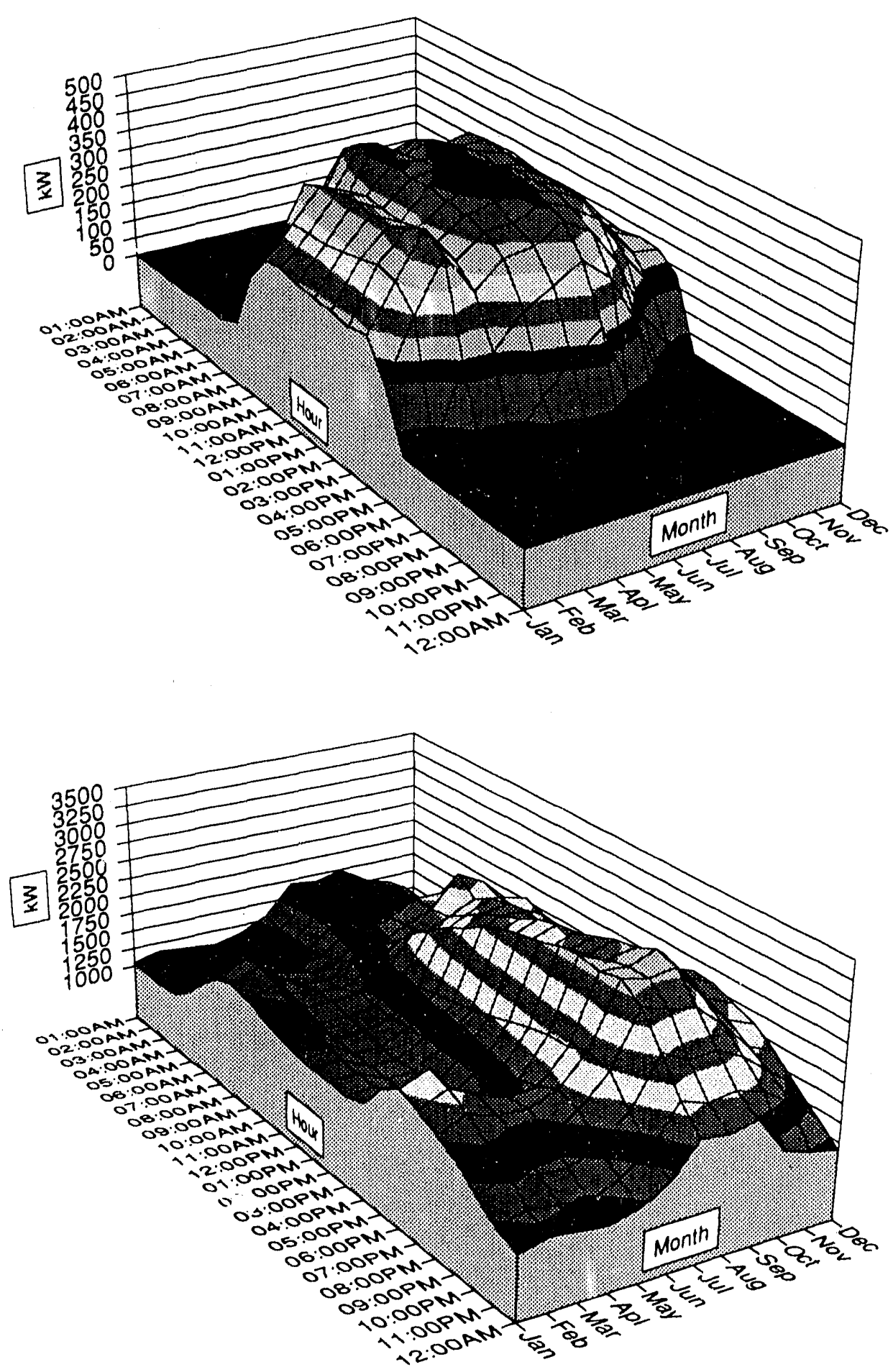

Figure 6-2. The average hourly generation for a 500-kW PV array peaks in the simmer months, closely matching the feeder load.

Figure 6-3. Reducing the feeder load by the PV generation leaves a much smaller load profile. power factor, high reliability, and adequate protection.

Figure 6-2 portrays the plant's average hourly output, shown to be higher and of longer duration in the summer months. This output was then subtracted from the estimated hourly loads of all feeders in the region. From the top 18 feeders, each showing reductions over $450 \mathrm{~kW}$, we selected a single feeder at the Kerman Substation with a 10.5 MVA transformer that was approaching its maximum capacity.

Figure 6-3 shows the reduced feeder load resulting when the simulated PV plant was interconnected to Feeder 1103. A comparison with Figure 1 shows a reduction of the feeder peak and, more importantly, a significant reduction in the number of critical hours of pe $\mathrm{k} k$ loading on the transformer. Further modeling showed a 5-year extension of the transformer's useful life. A 10.5MVA transformer would probably have been upgraded to $16 \mathrm{MVA}$, estimated to cost about $\$ 1,050,000$ in 1992 . Deferring this upgrade for five years has a value of $\$ 89 / \mathrm{kW}-\mathrm{yr}$, with another $\$ 10 / \mathrm{kW}-\mathrm{yr}$ added from benefits to line voltage regulators. The avoided cost of produced energy, equivalent to the product of simulated PV output and appropriate system power values, was determined to be $\$ 194 / \mathrm{kW}-\mathrm{yr}$.

Capacity benefits were calculated from the avoided cost of using a peaking gas turbine. In this standard methodology, turbine capital costs of $\$ 452 / \mathrm{kW}$ were multiplied by a levelized annual cost factor to obtain $\$ 65 / \mathrm{kW}-\mathrm{yr}$. Costs of annual overheads and operations and maintenance $(O \& M)$ were calculated to be $\$ 9 / \mathrm{kW}-\mathrm{yr}$. These were added to the annual gas turbine cost to yield a total annual cost of generation capacity of $\$ 74 / \mathrm{kW}$-yr. Finally, the total annual avoided generation cost was multiplied by $87 \%$ (to account for the estimated availability of PV during system peaks), yielding $\$ 65 / \mathrm{kW}-\mathrm{yr}$.

Transmission loss savings resulting from generation, transformer, and feeder loss savings were calculated as follows: 


\begin{tabular}{|c|c|c|}
\hline & $\begin{array}{l}\text { Real } \\
\text { Power }\end{array}$ & $\begin{array}{c}\text { Reactive } \\
\text { Power }\end{array}$ \\
\hline Distribution Feeder & $31 \mathrm{~kW}$ & 114 kVAR \\
\hline Transformer & $9 \mathrm{~kW}$ & $113 \mathrm{kVAR}$ \\
\hline Transmission System & $16 \mathrm{~kW}$ & $225 \mathrm{kVAR}$ \\
\hline Total: & $56 \mathrm{~kW}$ & 452 kVAR \\
\hline
\end{tabular}

Power flow calculations showed that the $500 \mathrm{~kW}$ array at the Kerman site would reduce peak reactive power losses by a surprisingly large $452 \mathrm{kVAR}$. With reactive power losses valued at $\$ 41 / \mathrm{kVAR}$, each $\mathrm{kW}$ of installed PV capacity would save $\$ 37$ in the first year. Escalating this annual savings over the life of the PV plant, the levelized annual value of reactive power loss savings was $\$ 67 / \mathrm{kW}-\mathrm{yr}$.

The base case also assumes an environmental adder of $10 \%$ of avoided costs. This is a conservative figure compared to estimates being considered or used by public utilities around the countiry.

Figure 6-4 shows the test case results. If the economic benefits of distributed PV are sufficiently large, small distributed PV installations will become cost competitive with other generation alternatives sooner than central station PV will (notwithstanding that central plants might be sited with $15 \%$ better annual insolation and constructed at 20\% less cost). This result holds even if the "soft" benefits of environmental credits and reliability evaluation are heavily discounted, because the other benefits such as electrical loss savings, voltage support, and higher reliability also exist and are quantifiable.

It is crucial to recall that these calculations pertain to a single specific feeder and site, and that generalization of these conclusions is strongly dependent on specific local factors. In fact, indiscriminate placement of generation in T\&D systems can result in detrimental impacts that could be greater than benefits described. At the projected 1992 cost of photovoltaic systems, use of PV to relieve the overloading of Feeder 1103 would be slightly more economical than a traditional distribution bank upgrade. This assumes availability of solar tax credits, fairly high customer valuation of reliability, and inclusion of an environmental adder. Even with these "soft" benefits, there are probably few cases where PV-T\&D would be economic in the 1992 time frame.

Extrapolation of the declining cost of photovoltaic systems indicates that distributed PV installations will become increasingly competitive in the future. Moreover, the magnitude of distributed benefits implies that advantages in decentralized modular generation could outweigh economies of scale of traditional centralized power generation. $\because$

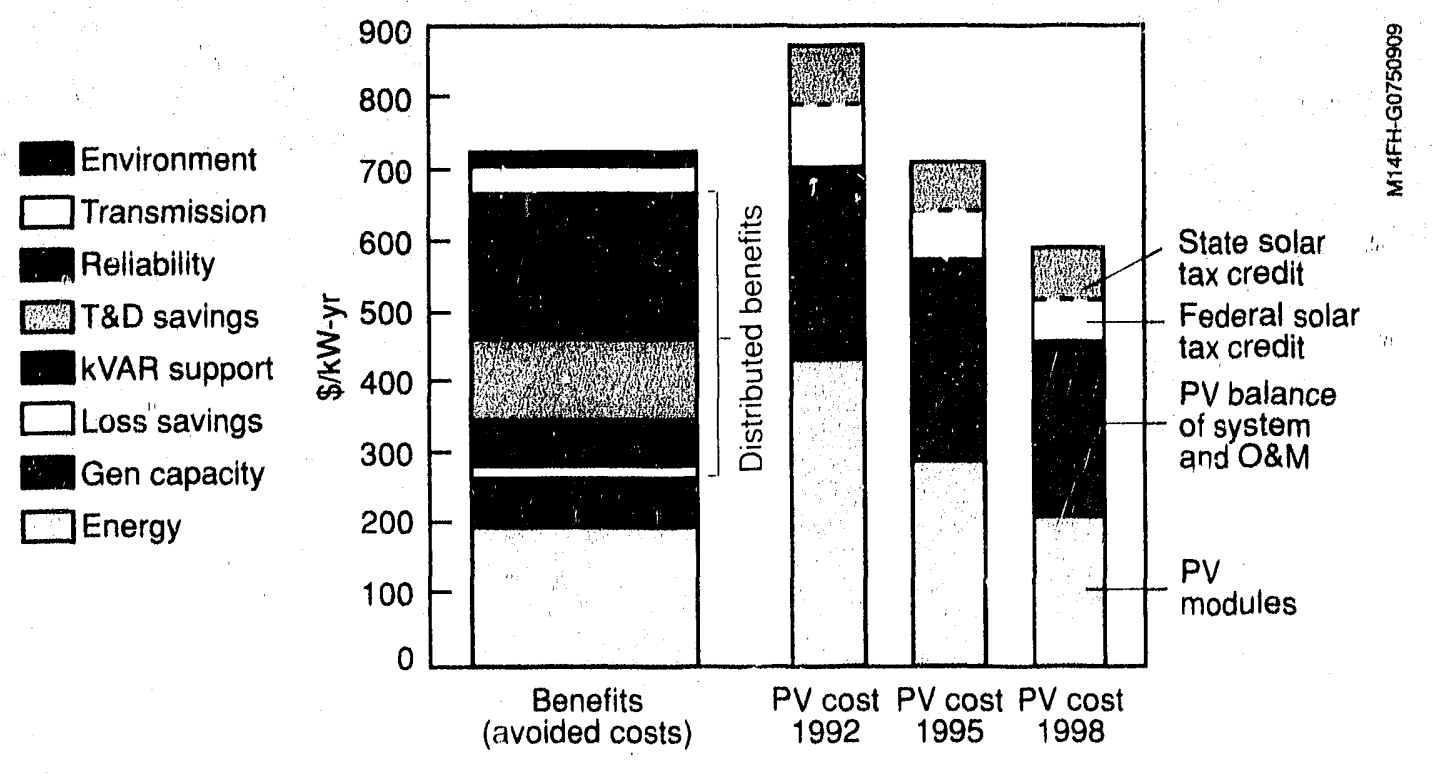

Figure 6-4. Avoided costs projected from interconnecting simulated PV plant with Feeder 1103. 


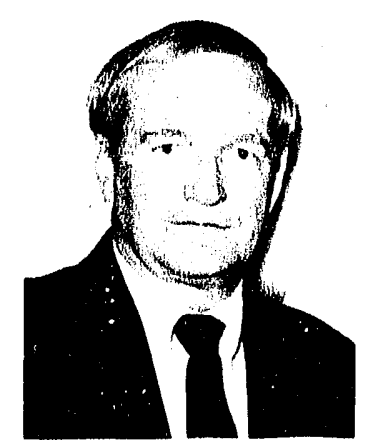

by J. Zabukover

General Manager,

K.C. Electric Association

I t may be a few years until photovoltaic power systems can compete with fossilfueled power plants in terms of cost-perwatt, but PV is already a success at our utility - and at today's hardware prices, too.

Our experience with PV has become legend in east central Colorado and has been repeatedly documented in the press. I've had to become adept at fielding questions from colleagues, some of whom were a bit skeptical back in 1989 when we first considered offering PV service. What follows is how I explained our decision to them.

K.C. Electric Association is a rural electric cooperative whose service territory is composed of some 4000 square miles of wide open spaces. We number approximately 6000 consumers served by 2700 miles of distribution line. Sales to irrigation consumers account for $52 \%$ of our total sales. Although 2045 consumers are concentrated in a few small communities, our total density is only two consumers per mile of line-and without those communities figured in, our density shrinks to 1.46 per mile.

K.C. Electric is very susceptible to winter storms, with the most severe weather occurring during March and April. These storms usually start with fog and drizzle that build ice on the lines, followed by strong winds that result in broken poles and downed lines. In 1988 we experienced a loss of 645 poles to these types of storms; in 1.989 the losses were closer to 1000 poles.
During one storm in 1989, I was at one of our offices fielding phone calls and greeting arriving ranchers, all of whom were asking the same question: "When will you have the electricity back on? My livestock need water." It doesn't help matters that these storms usually occur during calving season, and I noticed that many of the ranchers were filling their water tanks from town storage to haul out to their livestock.

I had also noticed that whenever there was a blizzard, the day after the storm passed the sky would be cloudless and we would have bright sunshine. As I sat there, I wondered about using photovoltaics to solve the problem of getting water to the livestock.

A few weeks later, we were discussing the concept of photovoltaic water pumping with Peggy Plate, a representative of the Western Area Power Administration (WAPA). We found out about WAPA programs that could help us with the costs/benefits analysis and with equipment selection, and we contracted with NEOS Corporation of Lakewood, Colo., to work with us on a concept. NEOS conducted a preliminary study that caught the attention of the Photovoltaic Design Assistance Center at Sandia National Laboratories. As a result, we were awarded a grant for the purchase of equipment to be used in a study, in return for reports concerning the project.

Our original purpose was to provide water to livestock. However, as we became further involved, we came up with the idea of using PV as an alternative 
to our line extension policy: consumers would be given a choice of contributing to the cost of building the line to a stock water well, or of installing a photovoltaic system. In either case, the equipment would be considered as utility plant and K.C. Electric would be responsible for maintenance.

Our biggest concern became determining a fair rate for a photovoltaic system. K.C. Electric does not have a separate rate for stock wells or fence chargers; they are included in the rural residential rate class. As a result, NEOS designed a rate based upon a cost recovery system that would allow K.C. to recoup its full equipment investment over a 20-year period. (K.C. Electric is having a costof-service study prepared in which the stock wells and fence chargers are separated from the rural residential rate class to determine a more accurate service cost. Preliminary studies indicate that our $\mathrm{PV}$ cost recovery rate will benefit both K.C. and the consumer.)

With our grant from Sandia National Laboratories, K.C. selected Remote Power, Inc. of Fort Collins, Colo., to provide equipment and installation. Our choice was based largely on Remote Power's experience with installing PV systems in undeveloped countries in Africa, the Middle East, and Far East. The company worked closely with us to engineer the project and solve any problems that arose.

K.C. Electric has now installed two systems. The largest system consists of a Solarjack submersible pump powered by ten Solarex panels on a Zomeworks tracker. The system pumps water 170 feet vertically and pushes it another $3 / 4$ of a mile to a stock tank, which feeds by gravity to four smaller watering tanks. Pumping capacity is seven gallons per minute, enough so that after the system was up and running, the consumer added an additional stock tank about a mile from the well.

The second system consists of a Solarjack pump of approximately $1 / 20$ of one horsepower, two Solarex panels and a Zomeworks tracker. The tracker has heated gas sensors that follow the sun from sunrise to sunset, giving the panels direct sunlight all day and providing peak performance. The system is portable and can be moved from location to location with a minimum of difficulty. It is also much cheaper than erecting an on-site windmill which, by the way, is non-portable.

We have now operated this smaller PV system at two well locations. The first well was 54 feet deep and pumped 65 gallons per hour. (The rancher who owned the well immediately ordered a system

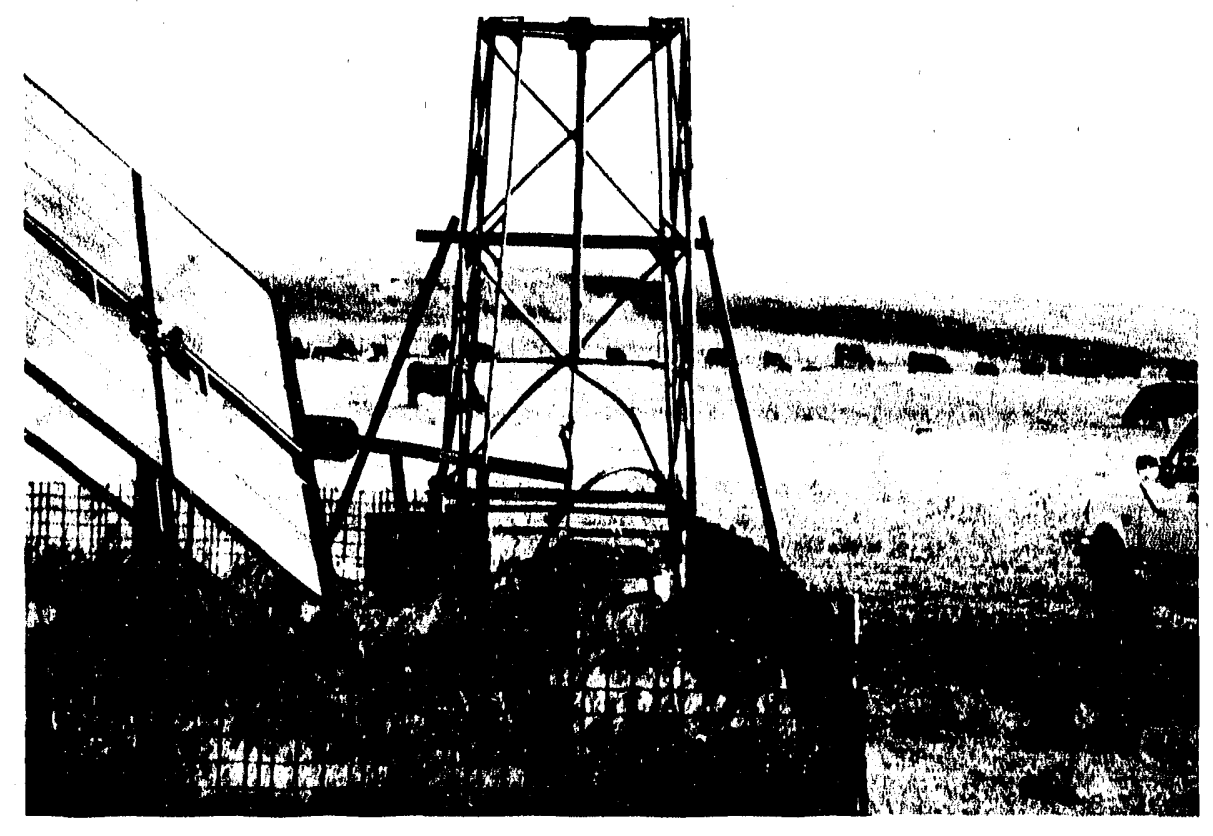

Figure 7-1. Stock well with pump power provided by PV array.

(Photo courtesy of K.C. Electric)

for himself, and is now planning on using the design in three separate wells.) The second test well is 230 feet deep and is now providing 45 gallons per hour. The small, submersible pump is light enough to be lowered into the well with no more than a garden hose, a rope, and the power source wires to the PV system. (We recommend that small-diameter cable be used in lieu of rope.)

Because our PV experiment inspired us to search for a separate rate class, we began gathering information on what portion of our utility plant was serving these remote stock well pump and fence charger loads. While a staff member and I were studying each service, compiling 
data on conductoring the number of poles, meters, etc., we saw another way that photovoltaics could help K.C. Electric.

Here is a typical situation we er."nuntered: one five-mile section of line served a total of five stock wells which, during our 13-month study period, provided the consumer with a total of only $125 \mathrm{kWh}$. Moreover, the entire load was from a single well pump that had been in operation for only one month of the entire period! If that line ever went down ..nd we replaced it, the costs of our servicing time alone would be far beyond recovery.

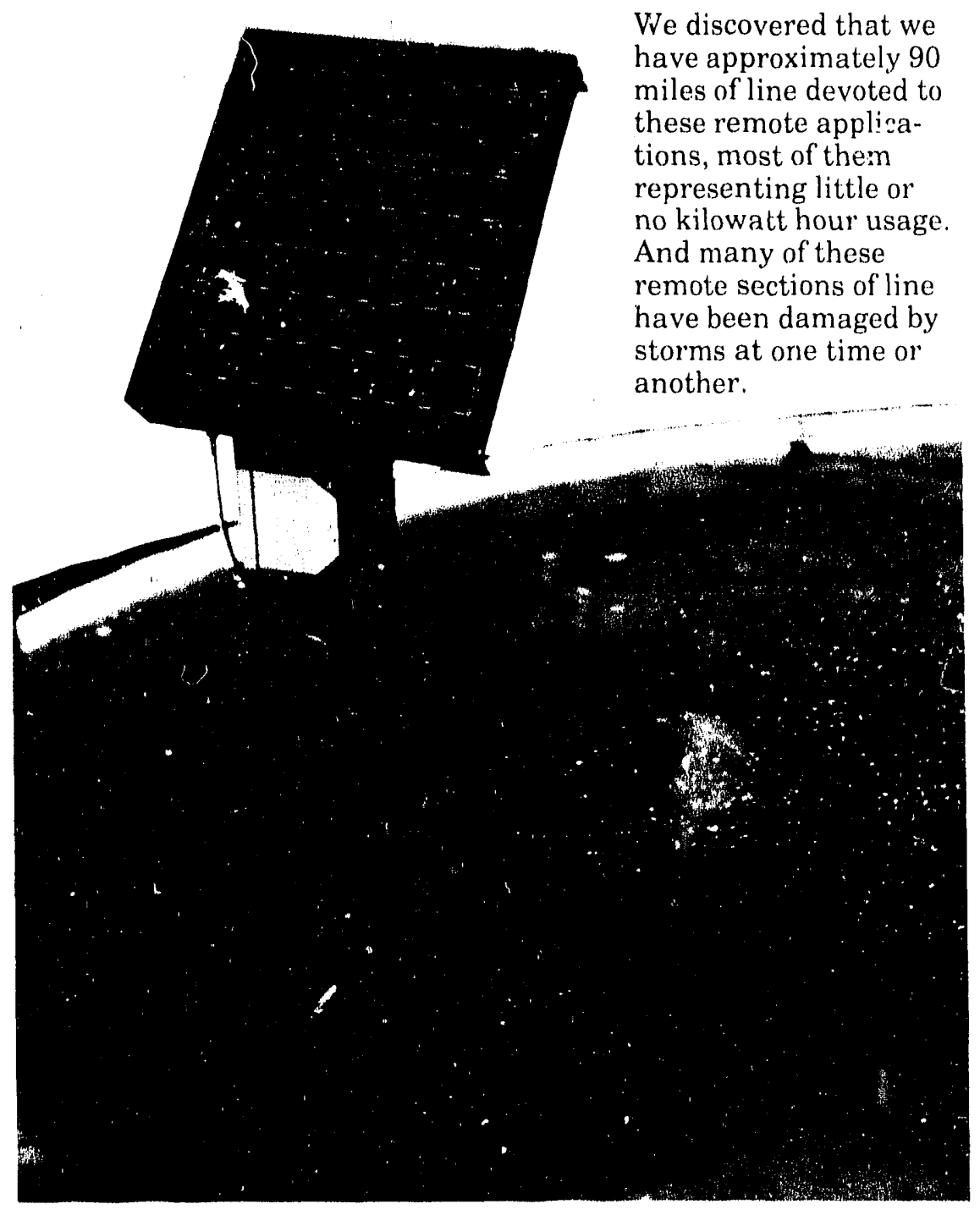

Figure 7-2. PV-powered stock tank de-icer. (Photo courtesv of K.C. Electric)
Today these sections of line comprise a data base so that the next time they are lost, we can evaluate installing a PV system at our cost rather than replacing the line. We estimate that rebuilding 90 miles of line $y^{\prime}: 11$ cost us close to a million dollars. Instead, we could replace the individual well units with ph stovoltaic systems (including panels, mount, pump and necessary wiring) at a cost of $\$ 1,800$ to $\$ 6,000$, depending on the depth of the well and the pump requirements. The typical savings would be substantial-without even considering the fact that if we pay instead to replace the line, the same section might go down again in years to come.

Each line section will have to be studied independently. Our data base will eventually include each section's past history and any facts that will help us make the decision on whether or not to rebuild. K.C. has prepared a consumer agreement to the effect that, if at a later date the consumer installs an additional load on a line replaced by PV, we will rebuild the line at our cost.

Meanwhile, our success with photovoltaics is prompting us to think about other applications at K.C. Electric. One that we are currently experimenting with is the PV stock tank de-icer. The panels provide power to a small air pump that pumps air through a hose to the bottom of the tank. The bubbles bring the warmer water from the bottom of the tank to the surface, melting a drinking hole in the ice. Once again, the rural consumer stands to benefit from PV technology. * 


\section{The Issues of Utility-Intertied Photovoltaics}

\section{The power conditioning subsystem (PCS) is the key to an effective interface between photovoltaic systems and utilities. Sandia National Laboratories provides guidelines for PCS design.}

\begin{abstract}
$\mathbf{I}$ In order for photovoltaics to realize its potential as a significant energy contributor, we must be able to make benign interconnections between PV systems and existing electric utility systems. The key to providing an effective interface between a PV system and the local utility is the power conditioning subsystem, or PCS (Figure 8-1, page 24). The PCS impacts four key issues of concern to utilities: (1) harmonic injections and their effect on the load; (2) the technical and economic implications of the PV system's power factor; (3) the potential for voltage flicker disturbances; and (4) the potential for "islanding" and for other system responses to dynamic utility conditions that would constitute a danger to utility personnel.
\end{abstract}

The dynamics of a utility require that the PV system respond properly to variations of a long-term nature, such as the change in voltage due to a voltage regulator change, or of a short-term nature, such as a surge caused by lightning or by switching. When there is a utility outage, the system must also respond properly by automatically disconnecting from the utility system.

At Sandia National Laboratories, we've developed guidelines for PCS design and have conducted a detailed engineering evaluation on resulting hardware, in part using an instrumented and controlled

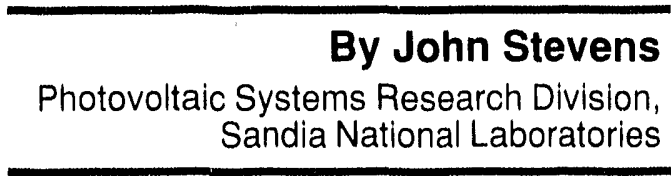

"utility" for full-power testing up to 75 kilowatts $(\mathrm{kW})$. A summary of findings, as they relate to those four areas of concern, follows.

Harmonics. Distortion in the power waveform-that is, the presence of frequencies other than 60 hertz $(\mathrm{Hz})$-is generally undesirable. Harmonics, frequencies that are integer multiples of $60 \mathrm{~Hz}$, are the most common type of distortion. Generally, low-order odd harmonics (3rd, 5th, 7th, 9th) are most common and most troublesome. Power at these frequencies can shorten the life of electrical devices by increased heating of electrical insulation and voltage stress due to coincident peaks in $60 \mathrm{~Hz}$ and harmonic frequencies. Harmonic injection into utility systems isn't unique to photovoltaics; rather, it is becoming more common with every new piece of electronic/magnetic equipment connected to the grid.

Although photovoltaic generating systems have the potential to inject significant quantities of harmonic current into a utility, the technology exists to ensure that this does not occur. In sizes at which the PV power conditioner can economically be a self-commutated unit switched at high frequency, the switching pattern can be such that the output waveform closely resembles a sinewave with low distortion. For 
instance, if a three-phase PCS is used, a line-commutated, 12-pulse inverter can be utilized, and easily filtered.

The impact of harmonics on a distribution system is determined by the system impedance; high impedance at a specific frequency results in high voltage distortion and in distortion at the terminals of a device. Impedance is increased by parallel resonance, which can bo viewed as a function of line loading and capacitor placement; however, relocation of shunt capacitors can alter the resonant frequency and the magnitude of the resonant impedance. Ir. addition, daily increases in load lower the impedance magnitude as well as shift the resonant point to a higher frequency.

These changes are exactly what is required if we are concerned about possible harmonic problems from PV systems. Utilities typically experience high load during the day, when the PV output is available, and low load at night, when the PV systems are off. Generally the daily load increase dampens the effect of harmonics at the same time of day that PV system output is high.

We instituted several studies of harmonics in actual grid situations, using the Institute of Electrical and Electronics Engineers (IEEE) Standard 519 for harmonic distortion as a baseline. IEEE 519 states that harmonics should be limited so that total harmonic distortion (THD) of the voltage waveform does not exceed $5 \%$ on primary distribution lines or $8 \%$ on secondaries (IEEE 519 is presently being rewritten). In one study, for instance, Oak Ridge National Laboratory and McGraw Edison jointly studied the "John Long Home" in Phoenix, which was part of a larger effort by John Long Homes that included a $190-\mathrm{kW}$ PV system serving 22 homes. The residential installation consisted of a $6.6 \mathrm{~kW}$ residential $\mathrm{PV}$ system with a low-frequency (high-harmonic) PCS on a 12.5-kilovolt line. Researchers measured the harmonics and simulated the impact of adding 100 such PCSs to two Arizona Public Service Company feeders.

In a worst-case scenario, line capacitors were arranged to make the system resonant at the third harmonic (the largest component of the PCS distortion) with absolutely no load installed. The simulated $550 \mathrm{~kW}$ of PV generation caused a $4.8 \%$ voltage THD (within the $5 \%$ limit) on one feeder and $6.2 \%$ on the other. When the same case was run with no shunt capacitors, the voltage THD was in the range of $2.5 \%$ for both lines. Using the worst-case capacitor arrangement, but with $2 \mathrm{MW}$ of resistive load on each feeder, THD was reduced to $3.6 \%$ for each. When all capacitors were connected, but with no load, the THD values were each $2.4 \%$.
Figure 8-1. The power

conditioning subsystem (PCS).

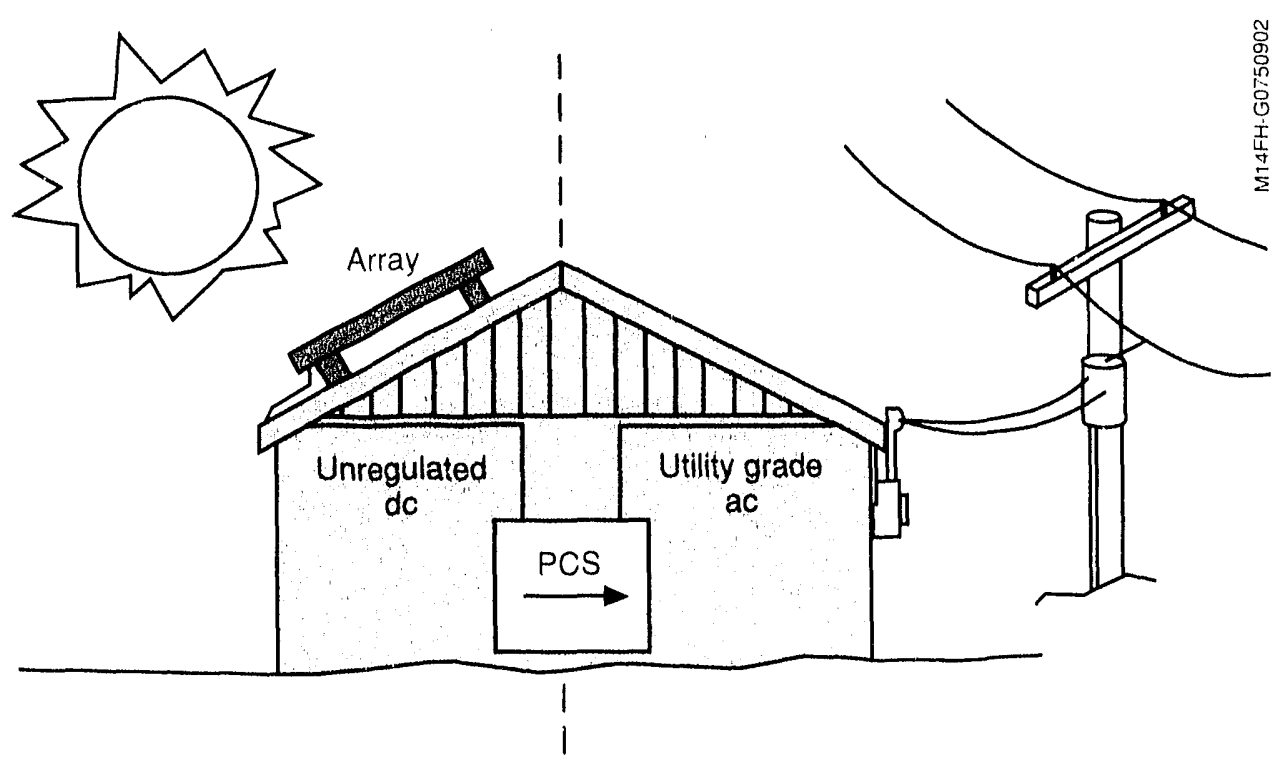




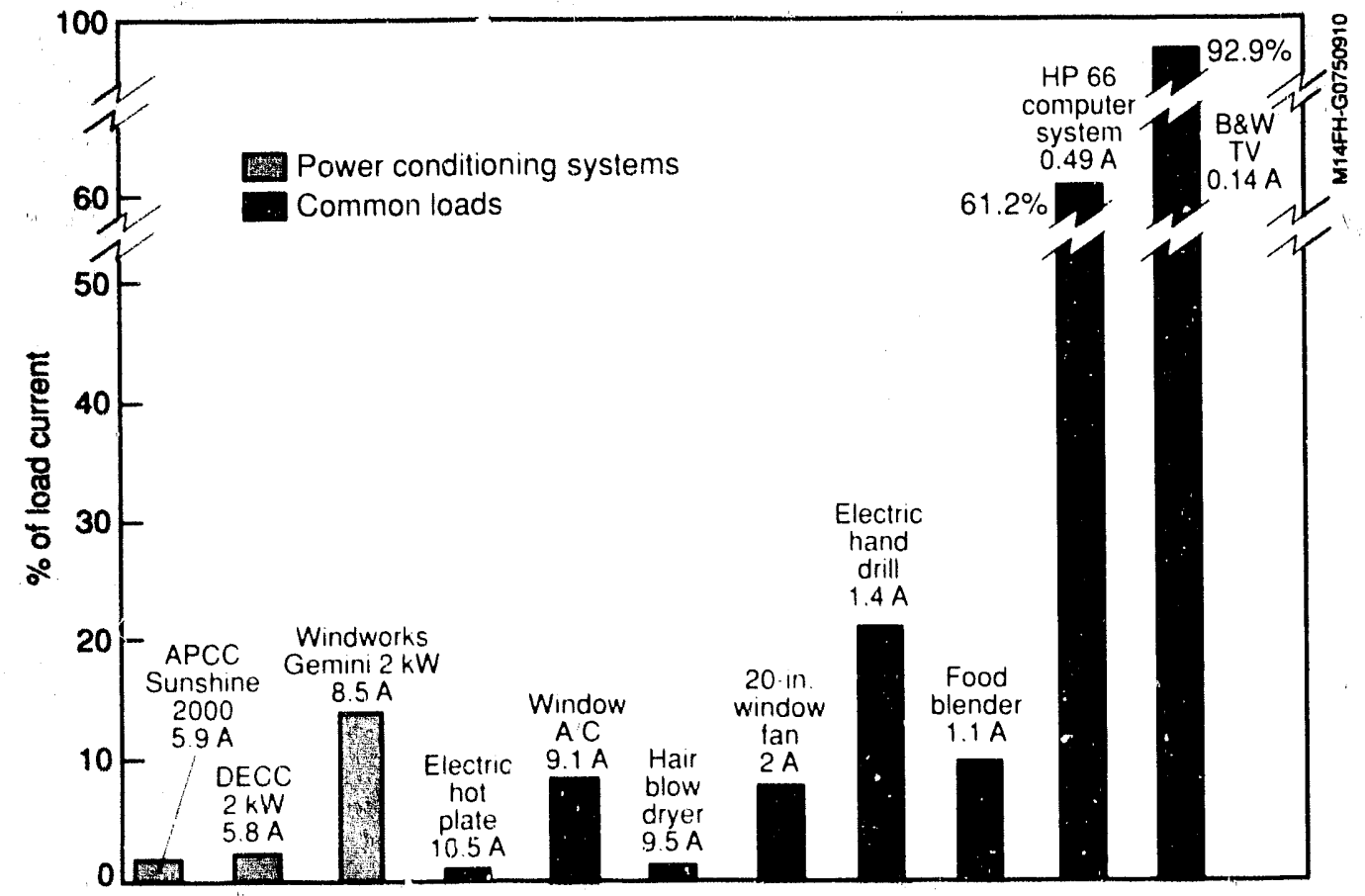

Other studies reinforce these results. The impact of dispersed small harmonic sources is dependent on line characteristics, particularly load and capacitor placement. If harmonic problems do appear. they can normally be resolved by manipulating capacitors. Scenarios that have realistic loads offer acceptably low THD.

The following report from Georgia Power Company (CPC I is a summary of the potential impact: "When GPC entered into this contract with sandia). we had serious misgivings about the effect that I PV-produced harmonics... would have on the utility system. Based on the percentage total harmonic distortion ...especially at low loads, this appears to be a problem. Howerer, microware orens, television sets, and home computers are frequently worse in terms of percentage THI). Taken in perspective the problem no longer seems as serious."

Power factor. Vars refer to reatetive volt-amps. power 90 out of phatse from watts. Power factor is a measure of the relative magnitudes of watts and vars that make up a load. ranging from zere

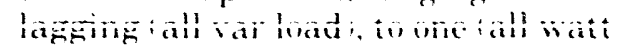

load / to zero leading (all capacitive load. actually supplying vars. Most homes have a power factor of roughly 0.9 laggring-suited for mostly resistive as opposed to inductive (motor) load. The reason power factor is an issue with PV systems is that line-commutated PCSs consume vars while delivering only watts in return, requiring the utility to buy wats while delivering vars for free

Power factor is basically an ecomomic rather than a system performance question. Writes a Southern California Edison encrineer: "In order to be completely equitable, it would be desirable to have the local (PV) generation supply' the reactive demand of the local load which it is carrying. Since this value would be impractical to determine, at reasonable compromise is to have the local generation operate at $1 .(1)$ pf so that, at heast, it does not impose any additional reactive demand..." This sugersts the use of a high-frequency Pe( 's designed to neither consume nor generate vals.

Flicker. Flicker is the dimming and brightening of lights caused by voltage finctuations, a soluce of customer com-

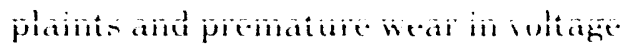

Figure 8-2. Current distortion (3rd harmonic) from power conditioning subsystems is comparable to or less than that from common household loads. 
regulating equipment. Flicker is related to var consumption: the current required to deliver vars imposes a voltage drop. just as the current to deliver watts does. Utilities must keep voltage within acceptable limits throughout the distribution system, but local PV generation will tend to cause a voltage increase near its own point on the feeder. Conversely, any reactive power demand by the local generation will cause voltage to fall. In a potentially adverse situation, such as an unusually large PV system on a very low capacity line, these two effects can be set to negate each other. Note that a properly calibrated PCS will not force the voltage out of limits, because the PCS has built-in voltage-limit trip points.

Cloud cover is another source of potential impact on voltage. Georgia Power, in assessing the impact of a $20 \%$ penetration of PV systems, determined that when local PV generation is reduced to $25 \%$ by a passing cloud, voltage would change $0.9 \%$, enough to cause a regulator step change. If such a cloud were to pass over a feeder once an hour, the result would be a $20 \%$ increase in regulator operations, with a resultant increase in maintenance and loss of equipment life. But such cloud patterns may not be that common. One Sandia study examined tivo feeders, one covering a service area roughly 1.2 by 2.5 miles, the other a rural service area some 8 by 14 miles. In order to obtain the $0.9 \%$ voltage change, the entire area containing PV systems must change from full sun to full cloud cover; this is possible, but it's probably not the normal situation. Other scenarios seem more probable, such as scattered cloudiness that would cause individual systems'
Figure 8-3. A test circuit for an intertied PV system's fault response.

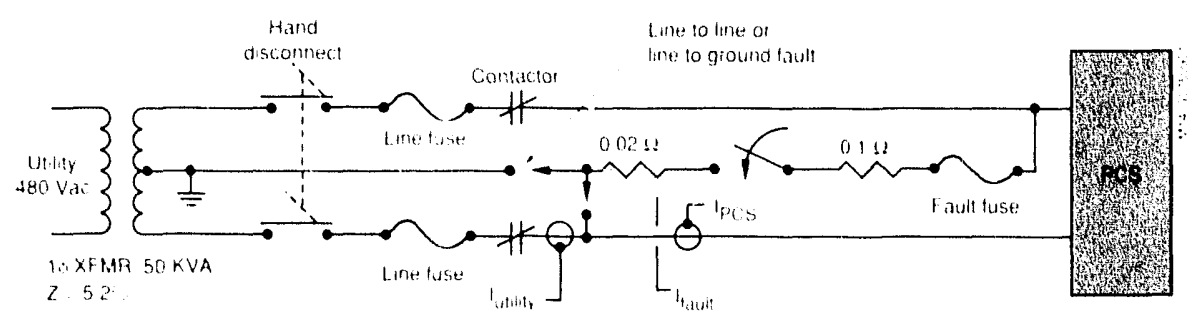

outputs to rise and fall but with overall PV generation remaining relatively constant. Changes on a larger scale, such as the movement of a cloud front, probably would occur less than once a day. However, utilities may want to perform cloudvoltage analyses for their own regions (a computer model is being developed). In a worst-case scenario, it might be necessary to operate the PV PCS at a fix or power fartor ( which is possible only with self-commutated PCSs).

Utility system dynamics. "Run-on" or "islanding," the possibility for a number of PV systems to fail to recognize a utility outage and to fail to disconnect, has been modeled extensively. The laboratory results are quite favorable.

Investigations show that there could be two different criteria for the time required before PCS disconnect. In the case of a fault, characterized by a voltage excursion, disconnect in 20 cycles or less is desirable to protect the PCS. In the case of manual disconnect, neither accompanied nor preceded by an excursion or followed by a reclosure, a disconnection simply must occur before personnel would touch the line-in reality several minutes, but perhaps one or two seconds to be totally satisfactory.

At tests performed at the Southwest Regional Experiment Station, Southern California Edison and Salt River Project, engineers modeled a variety of configurations, including five PCSs in parallel. using all combinations of resistive and reactive loading. The longest run-on time recorded was 19 cycles.

A circuit opening without a fault is a subtle event for a $\mathrm{PCS}$ to recognize. However, self-commutated PCSs work very well under most conditions; all of those tested would recognize a utility disconnect and respond properly when load watts or vars are more than $20 \%$ different than PV watts or vars. However, when the load is carefully selected for the PCS output, most units could be made to run on, in some cases indefinitely. Indefinite run-on, however, has a time limit, because generation and load are unlikely to remain constant. $\bullet$ 


\section{Photovoltaics for Large-Scale Use: Costs Ready to Drop Again}

\section{Look for economies of scale in crystalline silicon and good progress in thin-film and concentrator technologies.}

\begin{abstract}
A is still prohibitively high compa.ed with the cost of conventional forms of electricity generation, that picture is changing quickly, and for three reasons. First, the cost of PV-generated electricity has declined sharply during the last decade and will continue to fall. Second, PV systems are already competitive for select "high-value" applications, such as reducing a utility's peak load. And third,
\end{abstract}

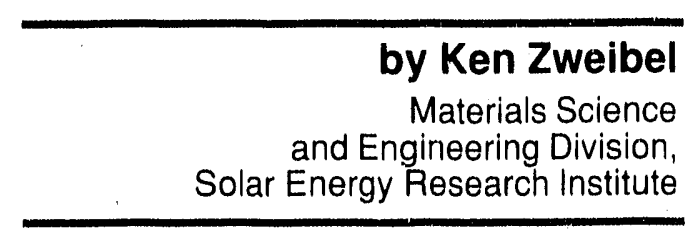

environmental cost add-ons associated with conventional electricity are rising rapidly.

These factors indicate that PV costs are likely to converge with those of conventional electricity during the 1990 s for several utility-scale applications. Technical progress has been so steady that reaching the lower costs required for much larger PV applications is

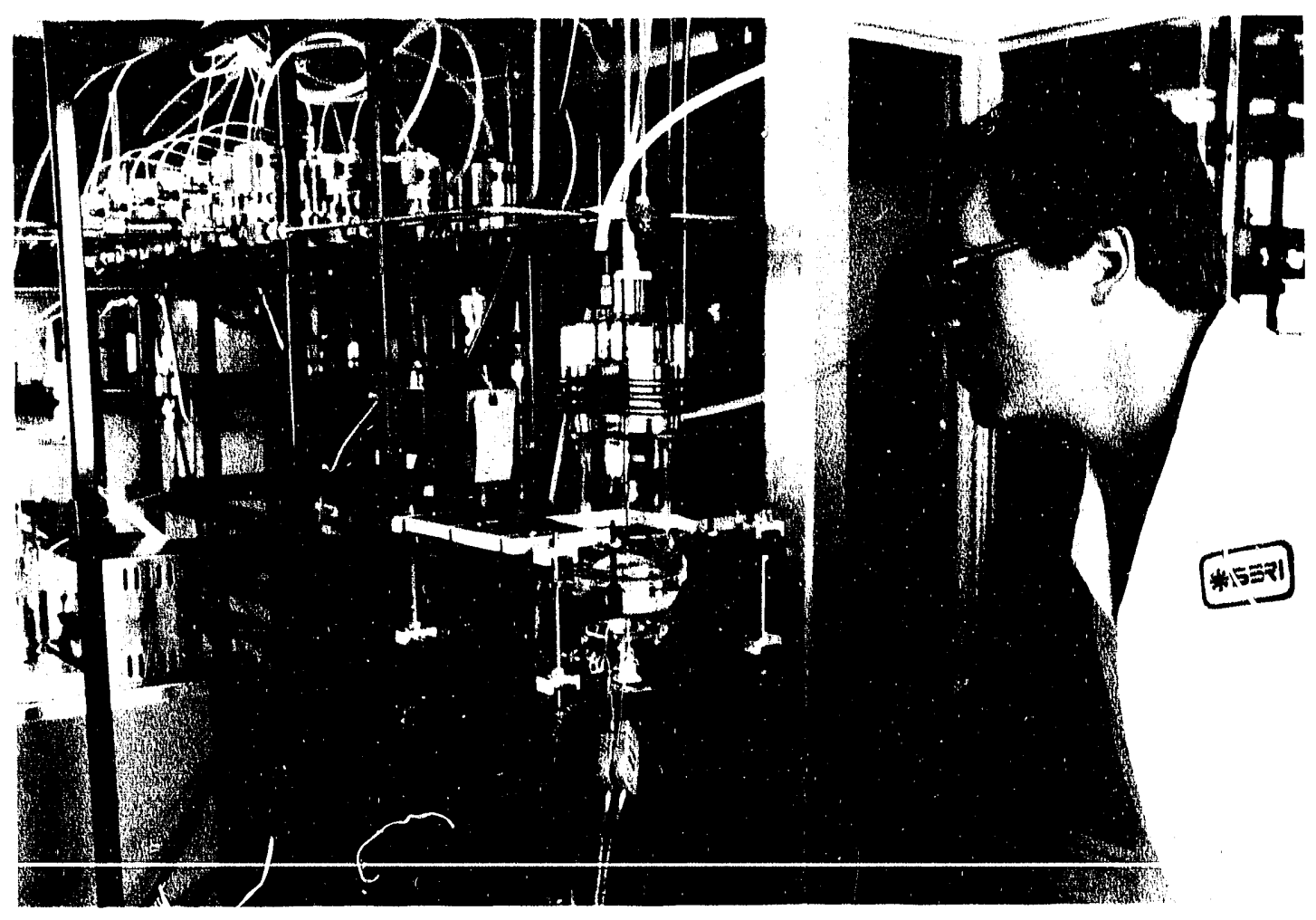

Figure 9-1. Researcher Mark Wanlass at the Solar Energy Research Institute developed a tandem PV cell consisting of layers of indium phosphide and indium gallium arsenide, each capturing a distinct portion of the solar energy spectrum. In concentrated sunlight (50 suns) the cell has delivered a conversion efficiency at $31.8 \%$ - a new SERI record. (Photo courtesy of Solar Energy Research Institute) 


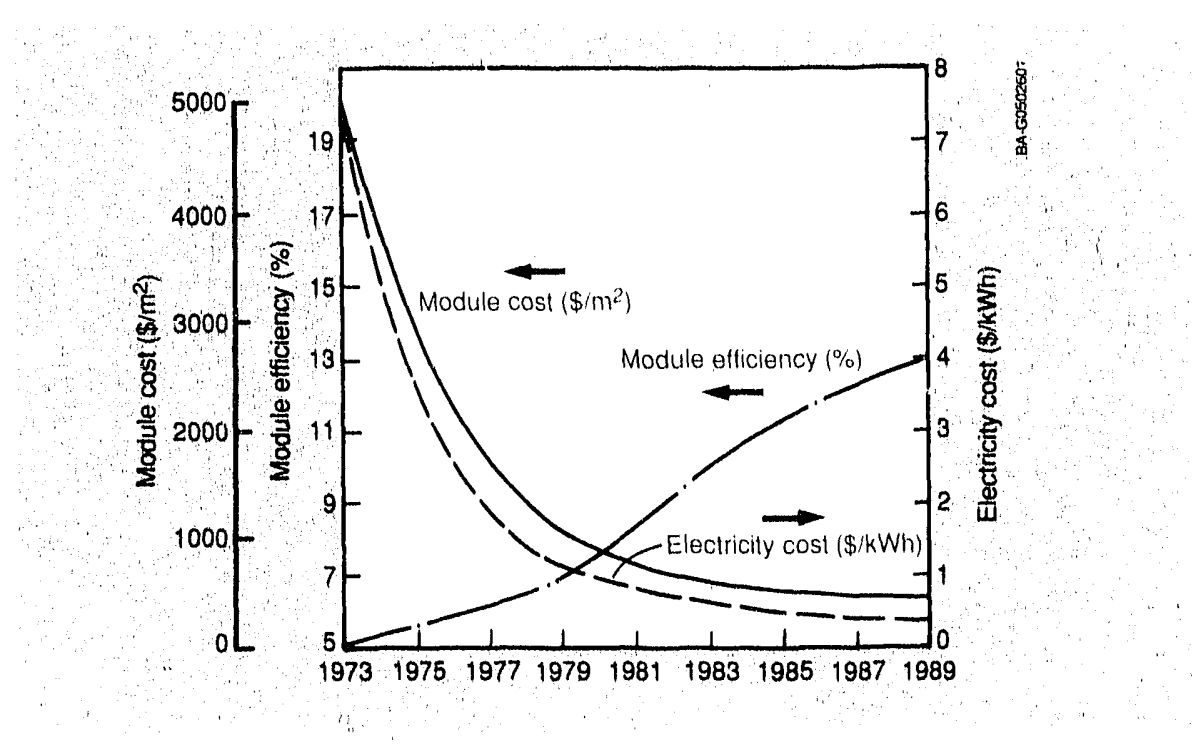

Figure 9-2. Reductions in the costs of modules made from crystalline silicon. the baseline PV technology, have combined with increases in module conversion efficiency to drive down the costs of $P V$ electricity. assured during the first decade of the 21st century.

The major cost components of a utility PV system include the PV module, a support structure (and perhaps a tracking mechanism), an inverter, associated wiring, land, installation, and indirect or overhead costs. The PV module thoroughly dominates these; it comprises about $80 \%$ of the total. As a result, any reductions in module costs greatly improve the costs of PV electricity as a whole (see box).

For locations with more intense sunlight, the cost of PV electricity will be proportionally lower; for those with less sunlight, proportionally higher. But one of the attractions of flat-plate PV is that the variation in cost across the United States is only $50 \%$ as a result of sunlight differences. If PV costs 64 per kilowatthour ( $\mathrm{kWh}$ ) in an average location like Kansas City, it will cost a little less in Albuquerque $(4.5 \phi / \mathrm{kWh})$ and a little more on Long Island $(7.2 \% / \mathrm{kWh})$.

Crystalline silicon. Figure 9-2 shows how the cost of the baseline PV technology, crystalline silicon, has dropped in recent years. In 1975, system costs were more than $\$ 4.00 / \mathrm{kWh}$; by 1980 , they had fallen to under $\$ 1.00 / \mathrm{kWh}$; today, they are near $\$ 0.35 / \mathrm{kWh}$. Three major factor's allowed the price of silicon PV to fall during the 1980s: higher module efficiencies, process optimization and automation, and reductions in the cost of the purified silicon feedstock. All of these trends continue today; module efficiencies will improve steadily as new device designs are incorporated into commercial products. Meanwhile, process development is making marked gains with such improvements as using multiblade wire saws to cut wafers from silicon ingots. In the past, wafer sawing resulted in about a $50 \%$ loss of the original silicon. Multiblade saws, however, can cut as many as 800 wafer's simultaneously, make cells thinner by half, and reduce materials losses by half.

\section{Calculating the Cost of a PV Module}

Three parameters determine module cost: manufacturing cost $\left(\$ / \mathrm{m}^{2}\right)$, module efficlency (\% sunlight transformed ir.s electricity), and module durability outdoors (years). When we know these parameters, we can employ a simplified calculation for the cost of PV electricity:

PV cost $(\$ / \mathrm{kWh})=$
$\frac{0.114 \cdot\left[\text { module }+ \text { BOS costs }\left(\$ / \mathrm{m}^{2}\right)\right]}{\text { module efficiency }(\%) \cdot 0.8 \cdot \text { annual sunlight }\left(\mathrm{kWh} / \mathrm{m}^{2}\right)}$
BOS (balance-of-system) costs include sup-
ports, land, and dc-to-ac inverters. Today,
such costs are about $\$ 120 / \mathrm{m}^{2}$ for fixed (non-
tracking) arrays; they are expected to fall to
about $\$ 65 / \mathrm{m}^{2}$ for fully optimized, large PV
installations. A second component is the
arlouni of incident suniighi, averaging about

$1800 \mathrm{kWh} /$ year for a U.S. fixed array. (About $25 \%$ more sunlight strikes a two-axis tracker, but array and maintenance costs are higher.)

The multipliers in the equation are 0.114 , which is the product of the annual payment rate on a 30 -year loan multiplied by a $25 \%$ indirect (or overhead) rate, and 0.8 , the factor that corrects for losses from higher operating temperatures, dust, wiring, etc. Conceptually, this is the same as finding the cost of a square meter of PV collector, dividing by its annual output of electricity, and then multiplying by a 30-year loan payback factor. Simplifying by using average U.S. sunlight, we obtain this:

$$
P V \operatorname{cost}(\$ / k W h)=
$$

$7.9 \cdot 10^{\cdot 5} \cdot\left[\right.$ module + BOS costs $\left.\left(\$ / \mathrm{m}^{2}\right)\right]$ modulte gffictonicy (\%) 
Similarly, as markets expand, production volumes will increase, enabling us to improve process throughput and increase automation. Overall, the cost of crystalline silicon modules should drop steadily throughout the 1990 s to about half today's levels or lower. Since module efficiencies will increase, the cost of PV electricity will drop to about half its current cost simply because of improvements in the baseline crystalline silicon technology. BOS costs will follow this trend; they will fall as more systems are manufactured.

\section{Thin films and concentrators.}

Although crystalline silicon makes an attractive picture of progress all by itself, it hardly describes the entire downward cost trend of PV. New technologies, including thin films and concentrators, promise to reduce mod.1 costs well below those of crystalline silicon. We predict that PV costs wil ultimately fall to as low as $6 \phi / \mathrm{kWh}$ (in average U.S. sunlight) in the first decade of the 21 st century.

Today, most of these innovative technologies are approaching prototype production; in terms of their learning curve, they are far behind crystilline silicon. But, by the same token, they have far more potential to imr rove. Thinfilm PV devices, for instance. are made with very thin layers of activ ? materials, as much as 100-300 times les $r$ material than that used in baseline silicon manufacturing. This permits tremendous cost reductions in materials and processing. Processing costs fall because thin films can be produced with low-temperature, rapid techniques like sputtering, spraying, and electrodeposition. In some cases, layers can be del,osited at several square meters $\left(\mathrm{m}^{2}\right)$ pe' ininute.

Another advantage is that thin films can be deposited on large surface areas. Baseline crystalline silicon cells are made on small wafers, and these re connected with soldered contacts. 'This connection step is clumsy and costly; with thin films, we can avoid it.

During the last decade, several promising candidate thin films have matured, among them copper indium diselenide,

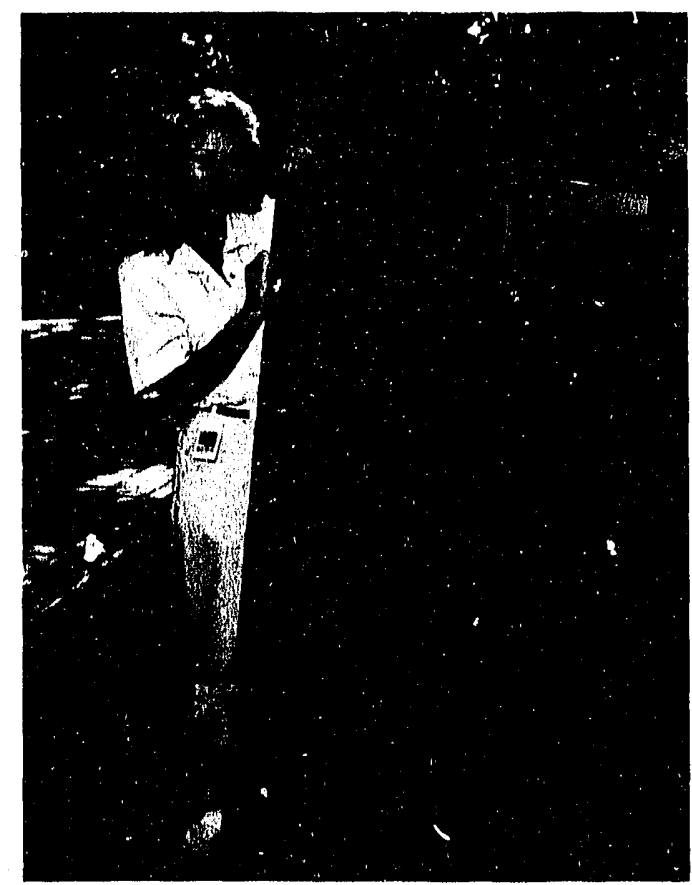

cadminm telluride, and amorphous silicon. Each was developed from scratch in competition with other thin-film materials, until candidate cells reached some proof-of-concept threshuld (e.g., $10 \%$ cell efficiency). Then lab-scale fabrication processes were chosen and cells were scaled up to submodules, which were followed by prototype and production modules. Today, a number of companies are positioned to begin commercial production of thin films; actually, some thin films have achieved minor market penetration in such consumer products as walk lights and calculators. But long-term module reliability has yet to be established, and current production levels do not permit fully optimized manufacturing procedures. Because thinfilm module efficiencies $(5 \%-10 \%)$ are lower than those for crystalline silicon modules, thin films still need some time to approa $h$ their low-cost potential.

All three thin-film materials have
produced square-foot modules with
efficiencies in the $9 \%-11 \%$ range. Amorphous silicon module efficiencies are somewhat overstated, because they degrade about $10 \% \cdot 25 \%$ during their first operational monch. Neither copper indium diselenide nor cadmium telluride have shown similar degradation. Copper indium diselenide technology is ahead of the others, because $9 \%$-efficient modules
Figure 9-3. Low-cost monolithic PV panels of amorphous silicon are being tested for widespread utility applications. (Photo courtesy of Solar Energy Research Institute) 


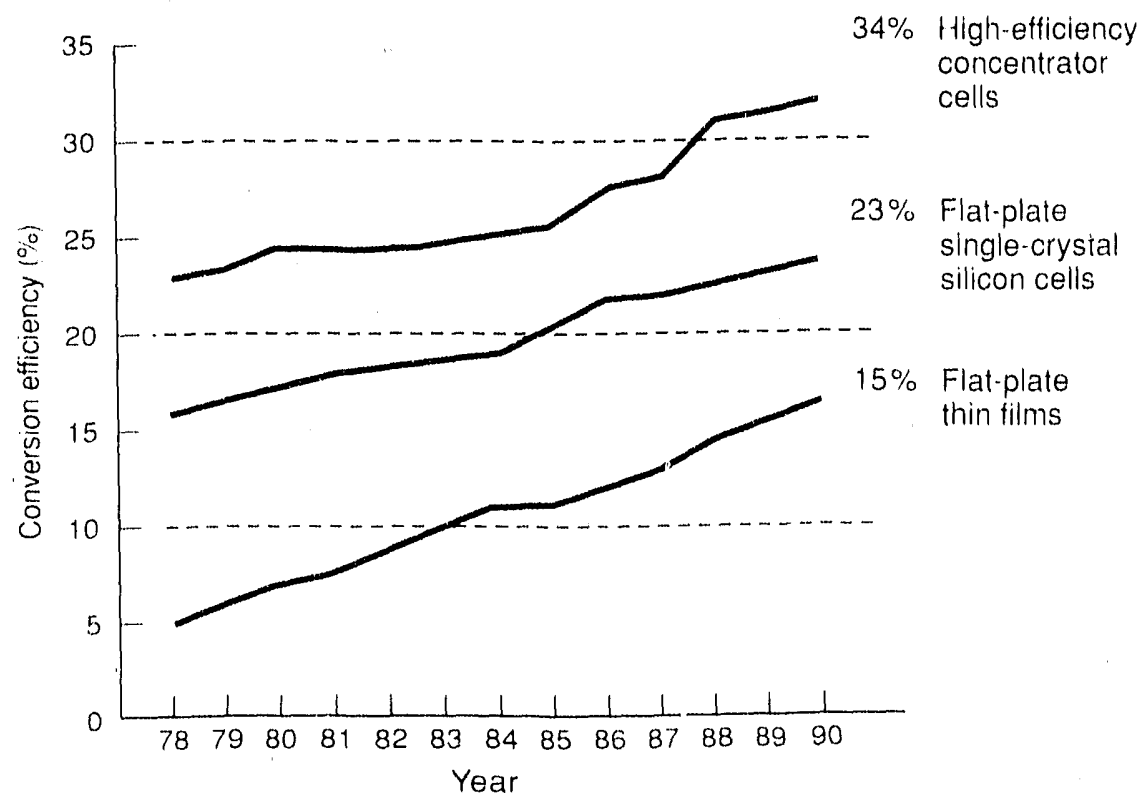

Figure 9-4. Progress in increasing the conversion efficiency of PV cells using concentrators has been near spectacular. in a size ( $\left.4 \mathrm{ft}^{2}\right)$ appropriate for power modules have now been fabricated. By 1995, thin-film modules that are $10 \%$. efficient and cost about $\$ 100 / \mathrm{m}^{2}$ should be commercially available. This would drop the cost of PV electricity to about half its current levels. Meanwhile, prototype modules should be nearing $15 \%$ efficiency.

Studies have consistently shown that the potential manufacturing cost of thin films is below $\$ 50 / \mathrm{m}^{2}$. A significant number of thin-film modules will be manufactured during the 1990s, and their costs will drop steadily as processes are optimized and economies of scale are incorporated. Efficiencies will also rise steadily, as will outdoor reliability. When commercial thin films can be made that are $15 \%$ efficient, at $\$ 50 / \mathrm{m}^{2}$, the cost of PV electricity (assuming parallel but less ambitious improvements in BOS costs) should average near $6 \phi / \mathrm{kWh}$. Since thin films appear to have this potential according to existing technological assessments, we can predict with confidence that these goals will be met.

Another innovative technology path with similar potential is concentrators. Concentrators use lenses or mirrors to focus light on small but highly efficient PV cells. Higher efficiencies are usually achieved, but costs are higher. Operating areas are also limited to relatively cloudless regions rather than areas like the eastern United States, where almost half the sunlight is diffuse.

Progress in cell efficiencies for concentrators has been near spectacular (Figure 9-4). Such progress is expected to continue as a new generation of devices based on stacking cells (multijunctions) matures. In the near term, the market potential for concentrators is limited to larger applications with sophisticated two-axis trackers. But as market scale increases, economical concentrators will become an attractive option in sunny areas.

The future. The exciting spectrum of PV technologies has already proven itself in terms of technical progress, and commercial progress now appears to be inevitable. Crystalline silicon technology is likely to lead the way, with significant cost reductions during the first half of the 1990 s as a result of commercial economies of scale. Although crystalline silicon technology is relatively mature, it has never been manufactured in any quantity. In the 1990s we will see those economies of scale. Meanwhile, thin-film and concentrating technologies will continue to progress, leading PV system costs to drop to about $10-154 / \mathrm{kWh}$ by 2000 .

As the new century begins, PV will be positioning itself to become a significant producer of electricity worldwide, worthy of consideration for about $10 \%$ of a utility's daylight demand. Such systems could be included on the grid either with no storage or with a small amount of dedicated storage to meet peak demand.

When PV reaches its ultimate low-cost potential (under $6 \notin / \mathrm{kWh}$ in an average location), it should be economical to incorporate electric storage and provide PV electricity on demand. By that time, utilities should be prepared to lead the way to even further cost reductions from the more sophisticated PV technologies that could emerge in the 21 st century. Among the possibilities: low-cost PV could be used to electrolyze water, producing clean-burning hydrogen fuels to replace fossil fuels. Such a possibility depends greatly on the technological progress now being made to reduce the cost of PV. $\because$ 


\section{Additional Information}

Ashley, S., May 1989, "New Life for Solar?" Popular Science, Vol. 234, pp. 117-121, 156, 158.

Bluestone, M., July 18, 1988, "Solar Power: Alive, Well-And Almost Making Money," Business Week, pp. 132-133.

Carlson, D., 1990, "Low Cost Power from Thin Film Photovoltaics," in Electricity: Efficient End-Use and New Generation Technologies, and Their Planning Implications, 'T.B. Johansson, B. Bodlund, R.H. Williams, eds., Lund University Press.

Chiles, J.R., January 1990, "Tomorrow's Energy Today," Audubon, pp. 60-72.

Cook, G., 1991, "Photovoltaics," The Encrgy Sourcebook: A Guide to 'Te'hnology, Resources, and Policy, R. Howes, A. Fainberg, ods., New York: American Institute of Physics, pp. $175-205$.

Corcoran, E., August 1988, "Sunny Prospects? Photovoltaic Technology Makes Slow But Steady Progress," Scientific American, Vol. 259. pp. 98-99.

"ID()E's Born-Again Solar Energy Plan," March 23, 1990, Science, Vol. 247, pp. 1403-1404.

Drewes, P., October-November 1989, "Capturing the Sun: Solar Power Brigincus a Northern Ontario Viliage," Canadian Geographic, Vol. 109, p. 60.
Dugan, R.C., "Harmonic Considerations for Electrical Distribution Feeders," Oak Ridge National Lab., Pub. ORNL/SUB81-95011/4, to be published.

Gulachenski, E., et al., January 1989, "Current and Voltage Harmonic Measurements and Modeling at the Gardner Photovoltaic Project," IEEE Transactions on Pouser Delivery, pp. 800-809.

Hoffner, J.E., "Analysis of the 1988 Performance of Austin's 300-kilowatt Photovoltaic Plant," Proceedings of the 1989 ASES Annual Meeting, Denver, Colorado, June 19-23, 1989.

Hubbard, H.M., April 21, 1989, "Photovoltaics Today and "Tomorrow," Science, Vol. 244, pp. 297-304.

Jennings, C., "Cost-Effective Photovoltaic Installations," Procecedings of IEEE PV Specialists Conference, May 1990, pp. 914-918.

Kapur, V.K., and B. Basol, 1990, "Key Issues and Cost Estimates for the Fabrication of CIS PV Modules by the Two-Stage Process," Proceedings of the 21st IEEE PV Specialists Conference, v. 1, pp. 467-470.
Kern, E.C., Jr., et al., "Cloud Effects on Distributed Photovoltaic Generation: Slow Transients at the Gardner, Massachusetts Photovoltaic Experiment," IEEE Transactions on Energy Conversion, June 1989, pp. 184-190.

Panico, D., "Decentralized Photovoltaics for Power Generation and Demand Reduction," Generation Planning Division, City of Austin Electric Utility Department, December 1989.

Smith, E.T., September 5, 1988, "Solar Power Is Nearing Its Day in the Sun," Business Week, p. 106.

"Steady Gains in PV Solar Cells Rekindle Utility Interest," April 1989, Research and Development, Vol. 31, p. 33.

"The Future of Solar Energy Just Got Brighter," January 18 , 1988, Business Week, p. 68.

Zweibel, K., 1990, Harnessing Solar Energy: The Photovoltaic's Challenge, New York: Plenum Publishing, $319 \mathrm{pp}$.

Zweibel, K., 1991, "Polycrystalline Thin Films," Chapter 9 in Fuels and Electricity from Renewable Sources of Energy, T.B. Johansson, H. Kelley, A.K.N. Reddy, R.H. Williams, eds., Prepared for the 1992 UN Conference on Environment and Development, Brazil (in press). 


\section{Key Contacts}

\section{American Solar Energy Society}

Larry Sherwood, Executive Director 2400 Central Avenue, Suite B-1 Boulder, CO 80301

(303) 443-3130

\section{Electric Power Research Institute}

3412 Hillview Avenue

Palo Alto, CA 94303

(415) $855-2000$

\section{Interstate Solar Coordinating Council}

John Dunlop, Chairman

900 America Center Building

St. Paul, MN 55101

(612) 296-4737

Sandia National Laboratories

Design Assistance Center

P.O. Box 5800

Albuquerque, NM 87185

(505) 844-2433

Solar Energy Industries Association

777 North Capitol Street, N.E.

Washington, DC 20005

(202) 408-0660

\section{Solar Energy Research Institute}

Technical Inquiry Service

1617 Cole Boulevard

Golden, CO 80401

(303) $231-7303$

\section{U.S. Department of Energy}

Office of Solar Energy Conversion

Photovoltaics Division

Forrestal Building, CE-131

1000 Independence Avenue, S.W.

Washington, DC 20585 
NOTICE: This report was prepared as an account of work sponsored by an agency of the United States government. Neither the United States

government nor any agency thereol, nor any of their employees, makes any warranty, express or implied, or assumes any legal liability or responsibility for the accuracy, completeness, or usefulness of any information, apparatus, product, or process disclosed, or represents that its use would not infringe privately owned rights. Reference herein to any specific commercial product, process, or service by trade name, irademark, manufacturer, or otherwise does not necessarily constitute or imply its endorsement, recommendation, or favoring by the United States government or any agency thereof. The views and opinions of authors expressed herein do not necessarily state or reflect those of the United States govf,rnment or any agency thereof.

Printed in the United States of America Available from:

National Technical Information Service

U.S. Department of Commerce

$$
\begin{aligned}
& 5285 \text { Port Royal Road } \\
& \text { Springtield, VA } 22161
\end{aligned}
$$

Price: Microfiche A01. Printed Copy A03

Codes are used for pricing all publications. The code is determined by the number of pages in the publication. Information pertaining to the pricing codes can be found in the current issue of the following publications which are generally available in most libraries: Energy Research Abstracts (ERA):

Government Reports Announcements and Index (GRA and 1); Scientific and Technical Abstract Reports (STAR); and publication NTIS-PR-360 available from NTIS at the above address. 
$-$ 

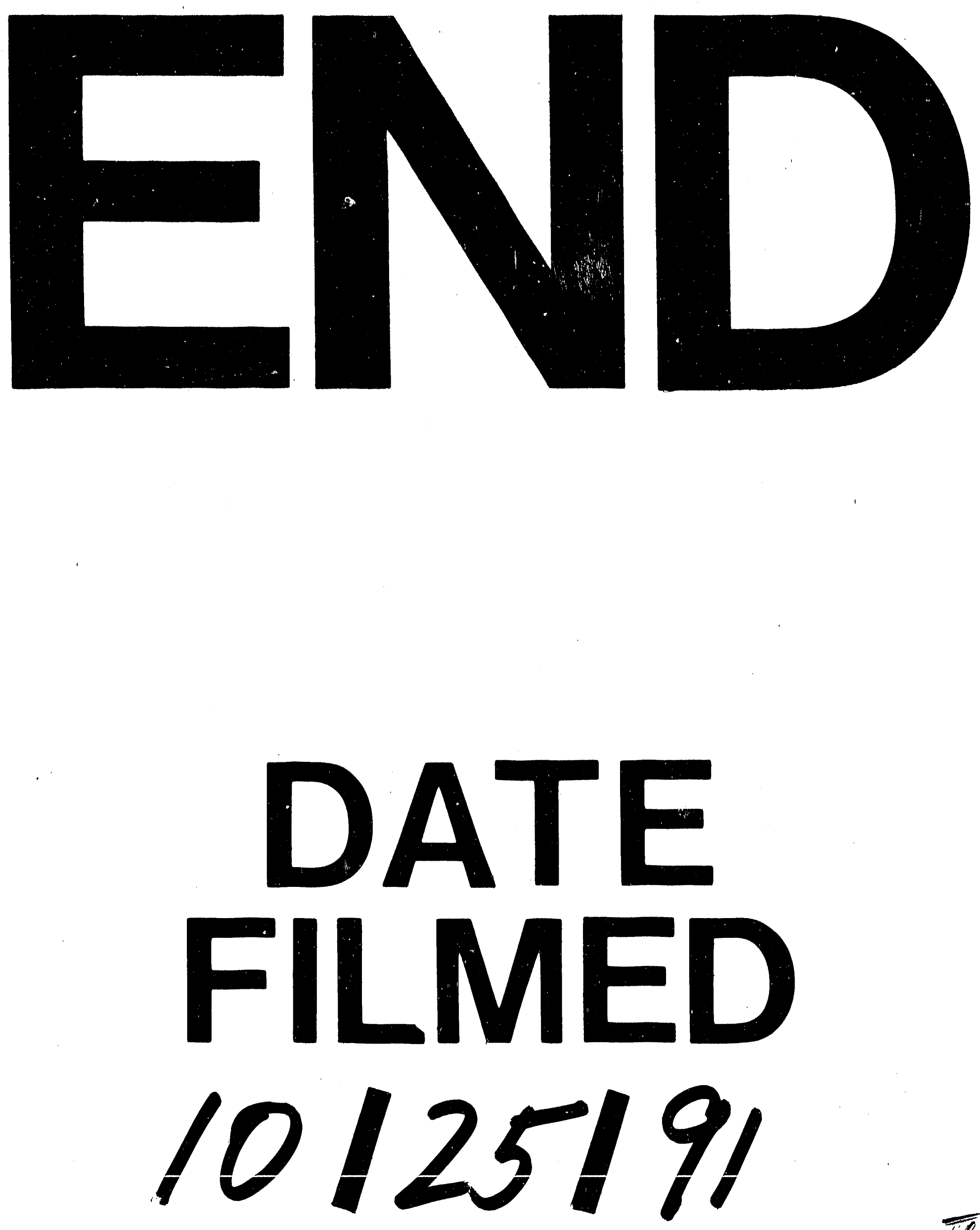
